Wildlife Program

Prepared in cooperation with the U.S. Fish and Wildlife Service and the U.S. Navy

\title{
Southern (California) Sea Otter Population Status and Trends at San Nicolas Island, 2017-2020
}

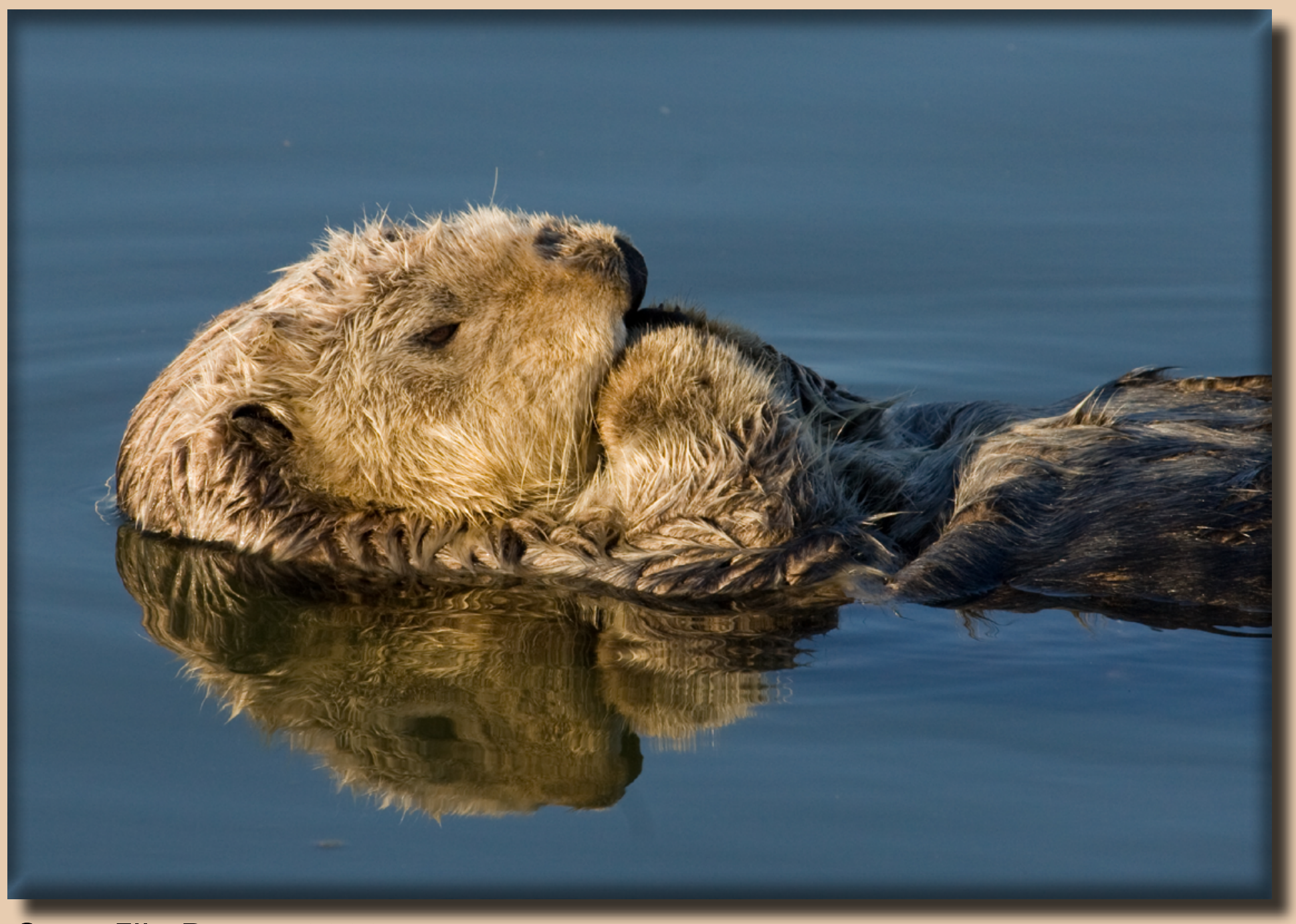

Open-File Report 2020-1115 
Cover Photo: A resting male southern sea otter, Moss Landing, California, February 3, 2009. 


\section{Southern (California) Sea Otter Population Status and Trends at San Nicolas Island, 2017-2020}

By Julie L. Yee, Joseph A. Tomoleoni, Michael C. Kenner, Jessica Fujii, Gena B. Bentall, M. Tim Tinker, and Brian B. Hatfield

Wildlife Program

Prepared in cooperation with the U.S. Fish and Wildlife Service and the U.S. Navy

Open-File Report 2020-1115 


\title{
U.S. Department of the Interior \\ DAVID BERNHARDT, Secretary
}

\author{
U.S. Geological Survey \\ James F. Reilly II, Director
}

U.S. Geological Survey, Reston, Virginia: 2020

For more information on the USGS - the Federal source for science about the Earth, its natural and living resources, natural hazards, and the environment—visit https://www.usgs.gov or call 1-888-ASK-USGS.

For an overview of USGS information products, including maps, imagery, and publications, visit https://store.usgs.gov/.

Any use of trade, firm, or product names is for descriptive purposes only and does not imply endorsement by the U.S. Government.

Although this information product, for the most part, is in the public domain, it also may contain copyrighted materials as noted in the text. Permission to reproduce copyrighted items must be secured from the copyright owner.

Suggested citation:

Yee, J.L., Tomoleoni, J.A., Kenner, M.C., Fujii, J., Bentall, G.B., Tinker, M.T., and Hatfield, B.B., 2020, Southern (California) sea otter population status and trends at San Nicolas Island, 2017-2020: U.S. Geological Survey Open-File Report 2020-1115, 38 p., https://doi.org/10.3133/ofr20201115.

ISSN 2331-1258 (online) 


\section{Acknowledgments}

This study was conducted in partnership with the U.S. Fish and Wildlife Service and the U.S. Navy, with assistance from the California Department of Fish and Wildlife and the Monterey Bay Aquarium. We thank the U.S. Navy for funding and facilitating this research project. We also thank Sophia N. Lyon for her support as survey lead on the summer 2019 survey and numerous field observers throughout the 2017-2020 sea otter surveys at San Nicolas Island, California, including (in alphabetical order): Heather Barrett, Lilian Carswell, Sarah Espinosa, Caroline Hempstead, Sophia Lyon, Claudia Makeyev, Michelle Staedler, and Colleen Young. We are grateful to Lilian Carswell and John Ugoretz for contributing to the study design and the inception of this project, to James Estes who established the San Nicolas Island sea otter monitoring program, and to Claudia Makeyev and Greg Sanders for facilitating the continuation of this project over time. This report was vastly improved by comments and suggestions made by Greg Sanders, Lilian Carswell, and Michelle Staedler, to whom we are especially grateful for their long-standing knowledge and expertise of the San Nicolas Island sea otter population beginning with the translocation and for their continued contributions to this project. 



\section{Contents}

Acknowledgments …...........................................................................................................................

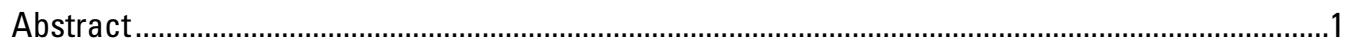

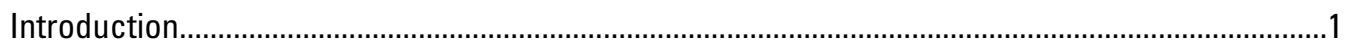

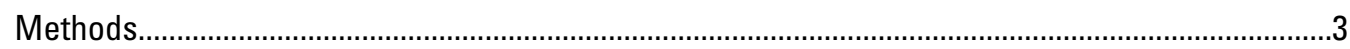

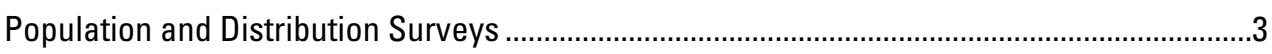

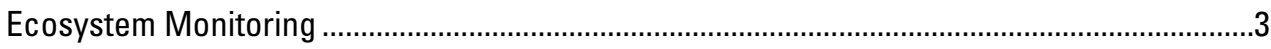

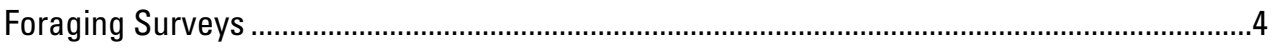

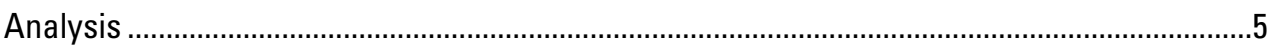

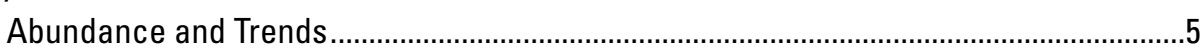

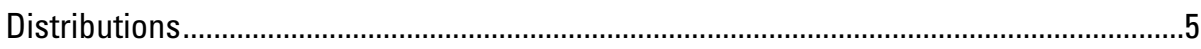

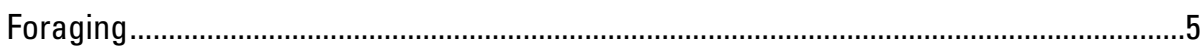

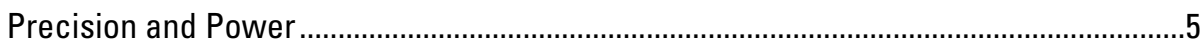

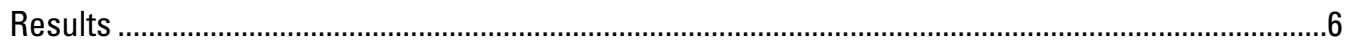

Abundance and Trends ....................................................................................................

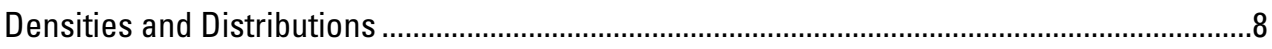

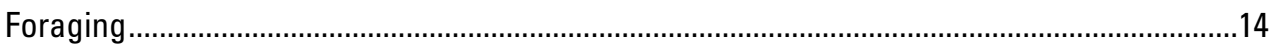

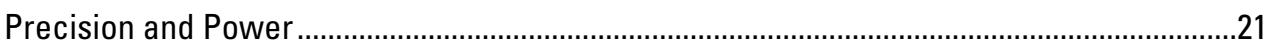

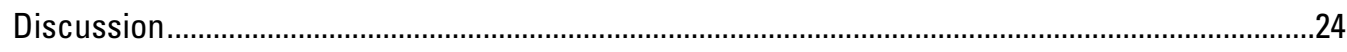

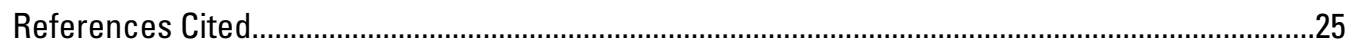

Appendix 1. Figures of Pages from the Monitoring and Research Plan for Southern Sea

Otter Military Readiness Area...............................................................................................27

\section{Figures}

1. Map of sea otter habitat within a 30-meter isobath around San Nicolas Island, California ...........................................................................................................

2. Graph showing number of sea otters counted at San Nicolas Island, California, during spring surveys from 1990 to 2019 ....................................................................6

3. Graph showing number of sea otters counted at all 9 areas at San Nicolas Island, California, during 13 seasonal surveys from February 2017 to February 2020......7

4. Graph showing estimated rates of annual population growth of sea otters at San Nicolas Island, California, over 3-year moving windows from 1990 to 2020, with 95-percent confidence intervals

5. Maps showing relative sea otter density during 3 years of fall and spring surveys taken around San Nicolas Island, California, from 2014 through 2016 and 2017 through 2019.

6. Map showing relative sea otter density during four seasonal surveys combined from 2017 through 2020.

7. Circular bar chart showing the average number of sea otters counted per year at nine survey areas around San Nicolas Island, California

8. Radial plots showing the abundance of sea otters around the periphery of San Nicolas Island, California, by season, 2017-2020

9. Maps showing seasonal distribution of relative sea otter density during surveys conducted annually in winter, spring, summer, and fall from 2017 to 2019, San Nicolas Island, California 
10. Graphs showing distribution of sea otters among three sections around San Nicolas Island, California, for seasonal surveys done from winter 2017 through winter 2020.

11. Graphs showing foraging outcomes of sea otters by year, including relative frequency at which prey items were observed and identified and rate of energy gain at San Nicolas Island, California, 2017-2019.

12. Graph showing relative frequency at which different species of sea urchins were observed in sea otter diets during two periods of foraging surveys at San Nicolas Island, California, 2003-2006 and 2017-2020.

13. Graphs showing foraging outcomes of sea otters by season, including relative frequency at which prey items were observed and identified and rate of energy gain at San Nicolas Island, California, 2017-2020.

14. Graphs showing foraging outcomes of sea otters by sex, including relative frequency at which prey items were observed and identified and rate of energy gain at San Nicolas Island, California, 2017-2020.

15. Graphs showing coefficient of variation when estimating population growth rate at San Nicolas Island, California, for moving 3-year trends during 2018-2021 and 2019-2022 when population trend $\lambda$ is reduced to less than 10 percent of the previous 3-year trend.

16. Graphs showing power of finding that the annual population growth rate, $\lambda$, at San Nicolas Island, California, for a moving 3-year trend in 2018-2021, 2019-2022, and both intervals has been reduced by greater than 10-percent lower than the annual growth rate from the previous 3 -year trend $(\lambda=1.22$ during 2017-2020), in other words, $\lambda<1.10$

\section{Tables}

1. Counts of independent sea otters and pups at San Nicolas Island, California, during spring surveys from 1990 through 2019

2. Count of independent sea otters and pups at San Nicolas Island, California, during seasonal surveys from winter 2017 through winter 2020, by area

3. Numbers of foraging bouts surveyed by season, sex, age class, and section of San Nicolas Island, California, 2017-2020, summarized by year and for all years combined.

4. Number of foraging dives observed by season and sex, and diving outcomes at San Nicolas Island, California, 2017-2020, summarized by year and for all years combined.

5. Number of successful dives with prey categorized into seven prey classes observed during two periods of foraging surveys at San Nicolas Island, California, 2003-2006 and 2017-2020. 


\section{Conversion Factors}

U.S. customary units to International System of Units

\begin{tabular}{ccc}
\hline Multiply & By & To obtain \\
\hline & Energy & \\
\hline kilocalorie $(\mathrm{kcal})$ & 4.184 & kilojoule $(\mathrm{kJ})$ \\
\hline
\end{tabular}

International System of Units to U.S. customary units

\begin{tabular}{lcl}
\hline \multicolumn{1}{c}{ Multiply } & \multicolumn{1}{c}{ By } & \multicolumn{1}{c}{ To obtain } \\
\hline & Length & \\
\hline centimeter $(\mathrm{cm})$ & 0.3937 & inch (in.) \\
meter $(\mathrm{m})$ & 3.281 & foot (ft) \\
meter $(\mathrm{m})$ & 1.094 & yard (yd) \\
kilometer (km) & 0.6214 & mile (mi) \\
\hline & Area & \\
\hline hectare (ha) & 2.47105 & acre \\
\hline
\end{tabular}

\section{Datum}

Horizontal coordinate information is referenced to the North American Datum of 1983 (NAD 83).

\section{Abbreviations}

$\mathrm{Cl} \quad$ confidence interval

COVID-19 Coronavirus disease of 2019

CV coefficient of variation

GLM generalized linear models

LOESS locally estimated sum of squares

SNI San Nicolas Island

SE $\quad$ standard error

USFWS U.S. Fish and Wildlife Service

USGS U.S. Geological Survey 



\title{
Southern (California) Sea Otter Population Status and Trends at San Nicolas Island, 2017-2020
}

\author{
By Julie L. Yee,1 Joseph A. Tomoleoni,' Michael C. Kenner,' Jessica Fujii,, Gena B. Bentall, 3,4 M. Tim Tinker, ${ }^{1}$ \\ and Brian B. Hatfield1
}

\section{Abstract}

The southern sea otter (Enhydra lutris nereis) population at San Nicolas Island, California, has been monitored annually since the translocation of 140 sea otters to the island was completed in 1990. Monitoring efforts have varied in frequency and type across years. In 2017, the U.S. Navy and the U.S. Fish and Wildlife Service initiated a sea otter monitoring and research plan to determine the effects of military readiness activities on the growth or decline of the southern sea otter population at San Nicolas Island. The monitoring program, at its basic level, includes quarterly seasonal surveys of population abundance, distribution, and foraging activity. From 2017 to 2020, we measured a 22-percent per annum increase in population abundance (95-percent confidence interval $=11-34$ percent $)$ with 114 total individuals as of February 2020. Coinciding with recent population growth, the sea otter distribution, which previously tended to concentrate on the west side, appears to have shifted toward an expansion of use in the north and especially greater seasonal use in the north and south during winter and spring. Foraging data were collected on a total of 2,675 foraging dives in 167 foraging bouts, and the majority of identified prey on successful dives $(\mathrm{n}=1,335)$ were sea urchins $(940)$ followed by snails (240) and crabs (78). Small numbers of lobsters (26), octopus (16), and abalone (5) also were identified. Estimates of energy intake rates averaged 17.3 kilocalories per minute (95-percent confidence interval $=15.6-19.0$ kilocalories per minute) and suggest possible variations across years and seasons, but confidence intervals based on specific years of data were relatively wide. In addition to abundance, trends, distribution, and forage energy intake across seasons and years, these replicated surveys provide information on the precision of data achieved by quarterly survey effort. We used precision estimates and conducted simulation analyses to assess the power of detecting 10-percent or greater decreases in population growth rates and how this power is likely to

1U.S. Geological Survey, Western Ecological Research Center, 2885 Mission Street, Santa Cruz, California, 95060

${ }^{2}$ Monterey Bay Aquarium

${ }^{3}$ Sea Otter Savvy

${ }^{4}$ Moss Landing Marine Laboratories change with years of observation, survey effort, and the size of decrease. These results can be useful to the planning of future monitoring and research of sea otters at San Nicolas Island.

\section{Introduction}

The southern sea otter (Enhydra lutris nereis), also known as the California sea otter, is a subspecies of sea otter (Enhydra lutris) native to California. Before the fur trade of the 18th and 19th centuries, sea otters were estimated to range from 150,000 to 300,000 individuals along the continental shelf of the northern Pacific Ocean from Japan through Mexico (Bodkin, 2015). Because of the fur trade of that period, sea otters were extensively hunted, and by the time of their protection under the North Pacific Fur Seal Treaty of 1911, they were nearly extinct. The California population was believed to be extirpated until a remnant group of about 50 sea otters was discovered near Big Sur, California. The southern sea otter population is listed as threatened under the Endangered Species Act of 1973 (ESA) and considered depleted under the Marine Mammal Protection Act of 1972 (MMPA). The surviving California population of sea otters gradually increased in range and number, reaching about 1,500 individuals by the mid-1980s. However, concerns remained about the survival of this population because of the narrow range of its habitat, particularly if an oil spill were to occur. The U.S. Fish and Wildlife Service (USFWS) developed a program to reintroduce up to 250 southern sea otters to San Nicolas Island (SNI), California, as a reserve population (USFWS, 2012). Despite the translocation of 140 sea otters between 1987 and 1990, less than 20 sea otters were counted at SNI for nearly a decade (table 1). Most of the translocated animals disappeared, but many returned to the mainland population and some moved to and stayed in other areas (Rathbun and others, 2000; Hatfield, 2005). From the beginning of the translocation, the USFWS and later the National Biological Survey and the U.S. Geological Survey (USGS) monitored the status and trends of this population. Spring and fall surveys occurred in all years, with the spring survey at SNI coinciding within several weeks of the mainland California sea otter census and up to four seasonal surveys occurring in some of these years. 
Table 1. Counts of independent sea otters and pups at San Nicolas Island, California, during spring surveys from 1990 through 2019.

\begin{tabular}{|c|c|c|c|}
\hline Year & Independents & Pups & Total \\
\hline 1990 & 14 & 3 & 17 \\
\hline 1991 & 14 & 2 & 16 \\
\hline 1992 & 10 & 2 & 12 \\
\hline 1993 & 7 & 4 & 11 \\
\hline 1994 & 10 & 4 & 14 \\
\hline 1995 & 9 & 4 & 13 \\
\hline 1996 & 12 & 4 & 16 \\
\hline 1997 & 16 & 0 & 16 \\
\hline 1998 & 12 & 2 & 14 \\
\hline 1999 & 18 & 3 & 21 \\
\hline 2000 & 21 & 2 & 23 \\
\hline 2001 & 21 & 5 & 26 \\
\hline 2002 & 22 & 5 & 27 \\
\hline 2003 & 33 & 5 & 38 \\
\hline 2004 & 27 & 4 & 31 \\
\hline 2005 & 22 & 3 & 25 \\
\hline 2006 & 36 & 5 & 41 \\
\hline 2007 & 26 & 4 & 30 \\
\hline 2008 & 22 & 3 & 25 \\
\hline 2009 & 27 & 6 & 33 \\
\hline 2010 & 38 & 7 & 45 \\
\hline 2011 & 44 & 6 & 50 \\
\hline 2012 & 48 & 10 & 58 \\
\hline 2013 & 54 & 8 & 62 \\
\hline 2014 & 59 & 9 & 68 \\
\hline 2015 & 54 & 7 & 61 \\
\hline 2016 & 92 & 12 & 104 \\
\hline 2017 & 72 & 9 & 81 \\
\hline 2018 & 81 & 14 & 95 \\
\hline 2019 & 109 & 12 & 121 \\
\hline
\end{tabular}

The U.S. Navy (USN) owns SNI and supported the translocation of sea otters to the island with a provision that defense-related actions were exempt from ESA consultation requirements (Public Law 99-625). After the USFWS declared the translocation program a failure, additional provisions for military readiness activities were legislated through the National Defense Authorization Act (NDAA) for Fiscal Year 2016. As required by the NDAA, the USN and the USFWS, in coordination with the USGS, developed a monitoring and research plan for the study of southern sea otters in the military readiness areas of SNI and San Clemente Island, which are both among the California Channel Islands (appendix 1). Of the two islands, sea otters are currently only known to occupy SNI. As a consequence, all monitoring efforts within this program were focused at SNI.

The military readiness area monitoring and research plan aims to "monitor interactions between military readiness activities and the sea otter population" (appendix 1). The plan defines three tiers of monitoring in order of increasing response to triggers that can indicate an impact to the SNI sea otter population from military readiness activities. The population is currently monitored in accordance to tier 1 ("basic monitoring and research"), in which the objectives are to (1) monitor and analyze population trends at SNI, (2) monitor and analyze subtidal benthic communities and assess impacts of sea otter recovery on food dynamics, and (3) determine factors affecting population change, including relative contributions of density-dependent factors (changes in per-capita prey abundance) and density-independent factors (for example, shark mortality, military readiness activities) to variation in growth rates. The plan prescribes a strategy in which any new military readiness activities that could affect sea otters would trigger increased (tier 2) monitoring (“operational monitoring"). Additional (tier 3) monitoring ("advanced monitoring") is triggered if, in addition to new military activities, one of the following three events occurs: (1) a dead, moribund, or stranded sea otter is found with injuries consistent with military activities is detected; (2) the population trend decreases by more than 10 percent from the average trend over the preceding 3 -year period for at least 2 consecutive years for reasons unattributable to density dependence; or (3) the total sea otter population drops below 75 .

The USGS serves the objectives of tier 1 by conducting quarterly sea otter population and foraging surveys and semi-annual subtidal kelp habitat community surveys consistent with long-term monitoring programs and by developing quantitative models that describe patterns of population change in correlation with environmental variables. This report presents information and analyses of data collected from the quarterly seasonal sea otter surveys from February 2017, the time of initiation of the military readiness area monitoring plan, through February 2020. The information collected from continuing surveys of the long-term subtidal kelp monitoring program are presented in a separate report (Kenner and Tomoleoni, 2020), and population dynamic models of the southern sea otter, including those at SNI, are in development.

Herein, we evaluate population abundance and distribution around SNI, and we analyze changes in these attributes across years and seasons. We analyze foraging activity and success outcomes, including prey distributions and energy intake. We also evaluate the power and effectiveness of current survey efforts to detect a population trend decrease in 2021 and 2022 by greater than 10 percent from the average trend over the preceding 3 -year period (2017-2020), which is a qualifying trigger for stepping up to tier 3 monitoring if new military activities were to occur. 


\section{Methods}

In this section, we describe the protocols we used at SNI to survey sea otter population abundance and spatial distribution, the subtidal kelp forest ecosystem, and sea otter foraging activity and outcomes. We then explain how we analyzed each of these components and calculated the power for detecting population trend decreases.

\section{Population and Distribution Surveys}

For this reporting period, winter surveys occurred from early to mid February, spring surveys in mid to late April, summer surveys in July, and fall surveys in late October to early November (as weather conditions and island access permitted). Surveys were conducted following similar protocols as the annual range-wide southern sea otter census in California (Hatfield and others, 2019) with the exception that an experienced observer surveyed alone at SNI (whereas a principal observer usually surveys with an assistant during the mainland range-wide census) and there were usually two or three attempts to count the entire island on different days of the survey trip. Each observer was assigned to one of nine survey areas on the island (fig. 1). Each survey area was divided into sections, and each observer was equipped with a high resolution 50-80X spotting scope (Questar Inc., New Hope, Pennsylvania) and binoculars (10X). The observers started at one end of their assigned section and selected an observation point that provided good vantage of a viewable area of habitat. In most cases observers used the same counting locations year after year, for consistency. The observers scanned the area with unaided eye and with binoculars for sea otters or objects that were suspected to be sea otters. Large groups and suspicious objects were scanned with the spotting scope. After sufficient time (15-30 minutes, depending on viewing conditions and extent) elapsed to make a thorough count of all sea otters within this first area of habitat, the observer moved to another location that provided good viewing of the next area of habitat, contiguous with the first area. This process was repeated until the entire section was counted.

These survey areas are grouped into three sections: west end (areas 1-3), north side (areas 4-6), and south side (areas 7-9). Area 3 is located completely offshore and nicknamed "The Boilers" for an expansive rocky outcrop with kelp beds 2-3 kilometers from shore that give the illusion of boiling water.

All sea otter observations were marked as points directly onto field maps that showed major stationary features of the area (shoreline configuration and offshore rocks) for reference.
Kelp beds from an earlier year also were displayed on these map sheets and could be used as a secondary reference due to their tendency to persist; however, surface kelp contracts, expands, and shifts amongst months and years and these printed images were not necessarily reliable for marking the precise locations of sea otters for comparisons across surveys. These features, regardless, allowed sea otter locations to be mapped relative to available visual cues within the same survey, which reduced the chances of double-counting or undercounting when the team moved to the next observation point.

To minimize double-counting or detection biases because of sea otter movements, each total island count included surveys of all nine areas of the island on one survey day. In addition to the sea otter locations, associated data recorded directly onto the maps included the number of independent sea otters, number and relative age of pups (pups are classed as either small or large depending on the presence or absence of the natal pelage, relative size, and behavior), behavior (resting, foraging, or other), group size, and micro-habitat type (open water or kelp). Time and general survey conditions also were recorded. Viewing conditions were rated from excellent to poor (coded 4 to 0 ). Shore-based surveys are estimated to detect about 90-95 percent of the sea otters located in the near-shore area (Estes and Jameson, 1988), but distances exceeding 1 kilometer $(\mathrm{km})$ offshore and factors such as viewing conditions and sea otter grouping and behaviors could influence detectability. Surveys were repeated on multiple days during each survey trip, and the maximum one-day total was taken as the island-wide count to minimize detection biases.

\section{Ecosystem Monitoring}

Subtidal kelp forest monitoring has occurred semi-annually in April and October in most years since October 1980, and information on these surveys through spring 2019 are reported in detail in a separate report (Kenner and Tomoleoni, 2020). In addition to subtidal kelp forest monitoring, we obtained multi-spectral imagery of the survey areas around SNI contracted by the U.S. Navy and taken by staff at Ocean Imaging Corporation (http://www.oceani.com, formerly also known as Atoll Ventures) annually during the fall of 2014 through 2019. These images were taken at 0.38 -meter resolution in red, green, blue, and near-infrared bands, and pixels were classified into exposed or submerged giant kelp canopies based on supervised learning algorithms. We obtained raster and shapefiles of these images and used geographic information systems (GIS) to develop maps of sea otter distributions relative to areas with kelp. 


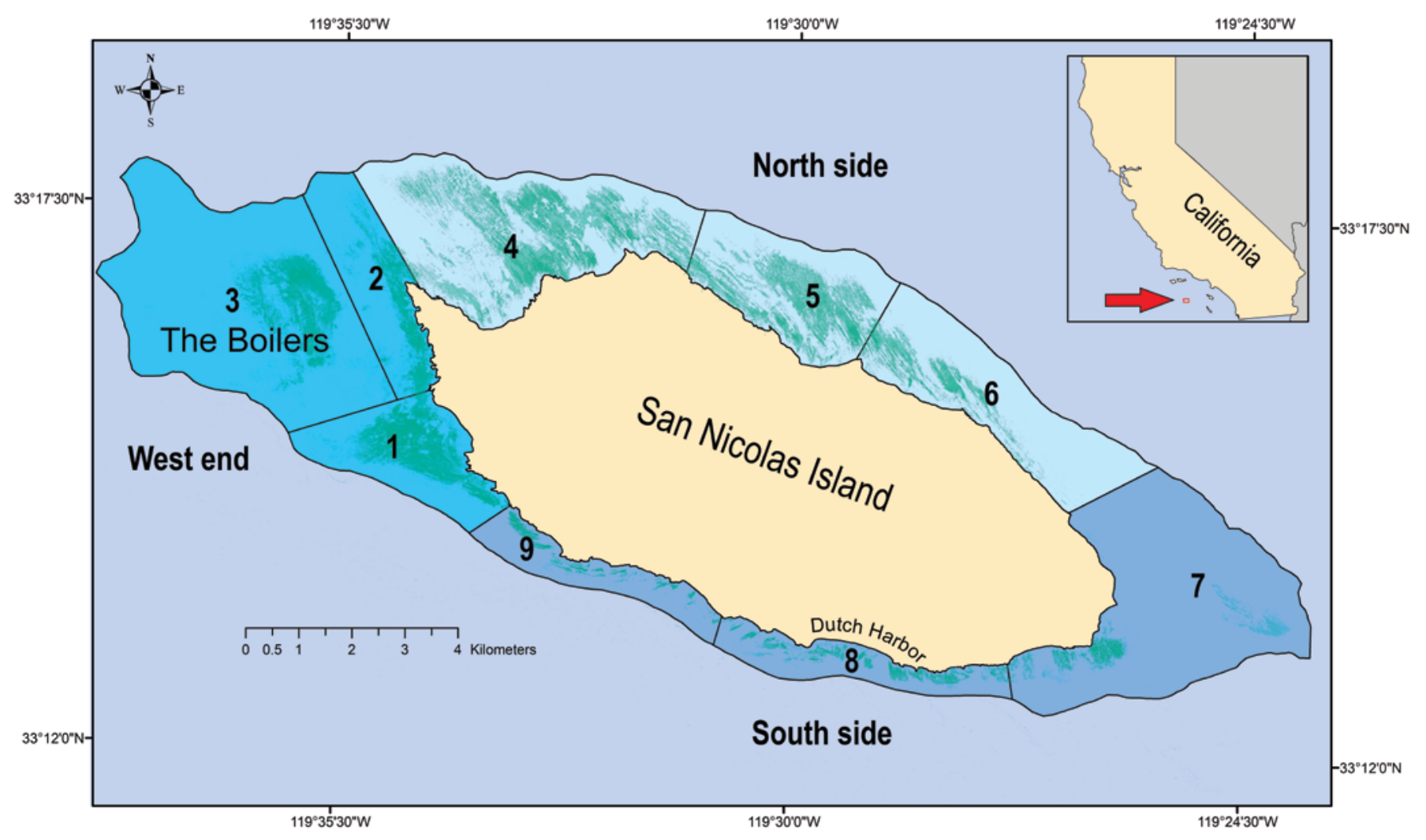

Figure 1. Sea otter habitat within a 30-meter isobath around San Nicolas Island, California. Sea otter counts are tallied into nine naturally distinct and contiguous survey areas numbered from 1 to 9 .

\section{Foraging Surveys}

Foraging data were collected during the same seasonal surveys on which population abundance and distribution were surveyed. Observation methods followed well-established protocols (Estes and others, 1981; Ralls and others, 1995; Tinker and others, 2008). Field observations were collected during daylight hours by teams of 1-2 observers searching for actively foraging sea otters near enough to shore where they could be visually distinguished from other sea otter individuals and monitored using a 50-80X spotting scope. Foraging bouts, which are defined as contiguous sequences of feeding dives made by the focal sea otter, were observed until data from at least 20 dives in the bout were recorded or until visual contact with the focal otter was lost. The information recorded during these bouts included date and time, area of the bout, duration of the subsurface dive interval (dive time) and the post-dive surface interval (surface time) for each feeding dive (in seconds), outcome of each dive (in other words, whether or not prey was captured), species of prey captured, number and size of prey items, per-item handling time (number of seconds required to handle and consume each item), whether or not tools were used to handle the prey, and ambient conditions (including sea-state, wind, and so forth). Prey size was recorded as the estimated diameter of the shell or maximum body dimension (excluding appendages), categorized into 5-centimeter incremented size-classes. Each 5 -centimeter increment represents one typical paw-width and was subdivided further into thirds within that size-class for increased precision. For observations where prey could not be reliably identified to species, the items in question were assigned to the lowest possible taxonomic unit. Any items that could not be reliably categorized to any taxonomic level were listed as unknown prey, although size class and number of items were still recorded. Additional information recorded by observers included numbers of prey items that were carried over from a previous dive or stolen by or from the focal animal and, in the case of females with dependent pups, the amounts of these prey that were shared with the pups. 


\section{Analysis}

\section{Abundance and Trends}

We modeled trends in island-wide sea otter abundance using nonlinear regressions fitted by locally estimated sum of squares (LOESS). We used generalized linear models (GLM) on 3-year moving intervals to estimate variable rates of population growth across time beginning with the 1990-1993 interval and ending with the 2017-2020 interval. We modeled sea otter counts $\left(C_{t}\right.$, for year $\left.t\right)$ within each interval by fitting a linear trend where replicate counts $C_{t}$ vary according to an overdispersed Poisson model with mean $\mu_{t}=\exp \left(\beta_{0}+\beta t\right)$ and variance $c \mu_{t}$. The multiplier $(c)$ in the variance represents an overdispersion factor, in other words, the amount by which the variance of count data exceeds that of a standard Poisson distribution, in which both the mean and the variance are $\mu_{t}$ (McCullagh and Nelder, 1989). We used the estimated slope coefficient $(\beta)$ to calculate and test multiplicative rates of annual change in population size, $\lambda=\exp (\beta)$, based on the mathematical result that the ratio in expected counts between two consecutive years $\mu_{t+1} / \mu_{t} \operatorname{simplifies~to~} \exp (\beta)$. For the 2017-2020 years, we included replicate counts from all four seasons $\left(C_{t, s}\right.$, for season $\left.s\right)$ and also tested for seasonal differences in island-wide total counts. We used $\mathrm{R}$ statistical software to conduct all statistical analyses and present graphics (Wickham, 2016; R Core Team, 2020).

\section{Distributions}

For the current series of quarterly surveys in 2017-2020, we analyzed sea otter distributions based on the area counts recorded on the high-count date for that survey trip. We used GIS to describe these distributions spatially for the years 2017-2019 when all seasonal surveys were conducted. No data were collected for spring and summer 2020 due to the suspension of field surveys on SNI resulting from the coronavirus disease of 2019 (COVID-19) pandemic. We used GLM to statistically test for changes in distributions among the years 2017-2020, seasons, and interaction effects.

We modeled spatial distributions by aggregating sea otter locations from the high-count dates across multiple survey trips, and we used kernel density estimation techniques with a 2-km smoothing parameter to model spatially explicit estimates of relative sea otter density. We evaluated this density for the aggregation of 10 seasonal surveys from October 2016 through February 2020. For reference to 2014-2016 when only semi-annual (spring and fall) surveys were conducted, we aggregated and compared spring and fall surveys from 2017 to 2019 . We used descriptive bar charts and circular charts that represent the periphery around SNI to analyze changes in sea otter distributions among the nine areas. For statistically analyzing changes in distribution, we aggregated the areas into three sections of the island (north side, south side, and west end) to ensure adequate sample sizes within each area category, and we used GLM to test for significant changes in distributions among years and seasons.

\section{Foraging}

We categorized foraging data into years (2017-2020), seasons (winter, spring, summer, and fall), and sex (males, females, and unknown) and examined prey composition within these categories in terms of the proportion of items within seven prey classes: abalone, crabs, lobsters, octopus, snails, urchins, and other. To obtain quantitative measures of the composition of various prey species in each individual's diet and energy intake rates (kilocalories per minute), field counts of prey capture frequency and prey shell diameter were converted to estimates of consumed biomass and caloric content using species-specific power functions for converting prey diameter to wet edible biomass and kilocalories per gram (Oftedal and others, 2007). These data were then analyzed using a Monte-Carlo simulation procedure to estimate diet composition (in terms of the proportion of consumed biomass contributed by each prey group) and rate of energy gain, or kilocalories consumed per minute of feeding (Tinker and others, 2008). The Monte-Carlo procedure incorporates sampling uncertainty and adjusts for recognized biases associated with direct observations of sea otter foraging: a detailed description of the algorithm is provided elsewhere (Tinker and others, 2012; Tinker, 2015). We repeated this analysis by groups of year, season, and sex.

\section{Precision and Power}

We used computerized Monte Carlo simulation analyses to evaluate the statistical precision and power of detecting whether the next two consecutive trends in the 3-year moving intervals, 2018-2021 and 2019-2022, have a greater than 10-percent decline compared to the preceding interval 2017-2020. We used the population trend model (GLM) fitted to the 2017-2020 interval of sea otter counts to determine (1) the last observed trend $\left(\lambda_{2020}\right)$ from which to simulate a greater than 10 percent decline and (2) the overdispersion parameter $(c)$ for those counts. We simulated sea otter counts for 2021 and 2022 using a range of annual trends $\left(\lambda_{2021}\right.$ and $\lambda_{2022}$ ) less than $0.9 \times \lambda_{2020}$, in other words, greater than 10 -percent decline from $\lambda_{2020}$. We simulated four seasonal surveys per year and subsampled from these simulations to compare to a reduced effort of 1,2 , or 3 surveys per year. Because seasonal survey counts varied within year but did not vary in seasonally predictable ways, we modeled seasonal survey counts (in other words, $C_{t, s}$ for season $s$ and year $t$ ) as replicate observations from Poisson distributions with means based on the simulated decrease in $\lambda$ and overdispersion $c$. We applied the decreases to the last counted island-wide population total from the February 2020 survey. 
For each simulated dataset, we modeled and estimated trends $\left(\lambda_{\text {sim }}\right)$ and associated 95-percent confidence intervals (CI) to quantify the uncertainty anticipated with each survey effort. Because a 95-percent $\mathrm{CI}$ range represents approximately 4 standard errors (SE; 2 on either side of $\lambda_{\text {sim }}$ ), we estimated $\mathrm{SE}$ as the length of the 95 -percent $\mathrm{CI}$ divided by 4 . We then calculated coefficient of variations (CV) as SE divided by $\lambda_{\text {sim }}$. Because precision is inversely related to $\mathrm{CV}$, smaller values of $\mathrm{CV}$ represent greater precision. Also for each simulation, we noted whether $\lambda_{\text {sim }}$ would have been deemed significantly lower than $0.9 \times \lambda_{2020}$ by examining whether the 95 -percent CI for $\lambda_{\text {sim }}$ is less than $0.9 \times \lambda_{2020}$. We repeated this process for 50,000 simulated datasets, and we calculated statistical power as the proportion of simulations in which the 95 -percent CI for $\lambda_{\text {sim }}$ was less than $0.9 \times \lambda_{2020}$. Because our power to detect a greater than 10-percent decrease in trend should increase with greater decreases in trend, we repeated the power analysis for multiple values of hypothetically reduced trends ranging from as low as 0.9 to as high as $0.9 \times \lambda_{2020}$, in increments of 0.01 . We repeated these calculations for 1, 2, and 3 seasons to assess the reduction in statistical power with fewer seasonal surveys per year.

\section{Results}

In this section, we report sea otter population abundance and trends, spatial densities and distributions of sea otters, distributions of kelp, sea otter foraging success, and relative frequencies of prey consumed. We also present power calculations for detecting population trend decreases of greater than 10 percent from the latest 3-year (2017-2020) trend $\left(\lambda_{2020}\right)$.

\section{Abundance and Trends}

Shortly after translocation, most sea otters departed SNI, leaving a population of less than 20 sea otters during most of the first decade (table 1). However, this population had gradually grown to exceed 100 individuals by the time of the spring 2016 survey (fig. 2). As is typical with count data, survey counts became more variable with increased population size, but it is unclear what else could have contributed to variable counts during the last several spring surveys. However, greater than 100 individuals were consistently counted during the last 6 surveys (table 2; fig. 3).

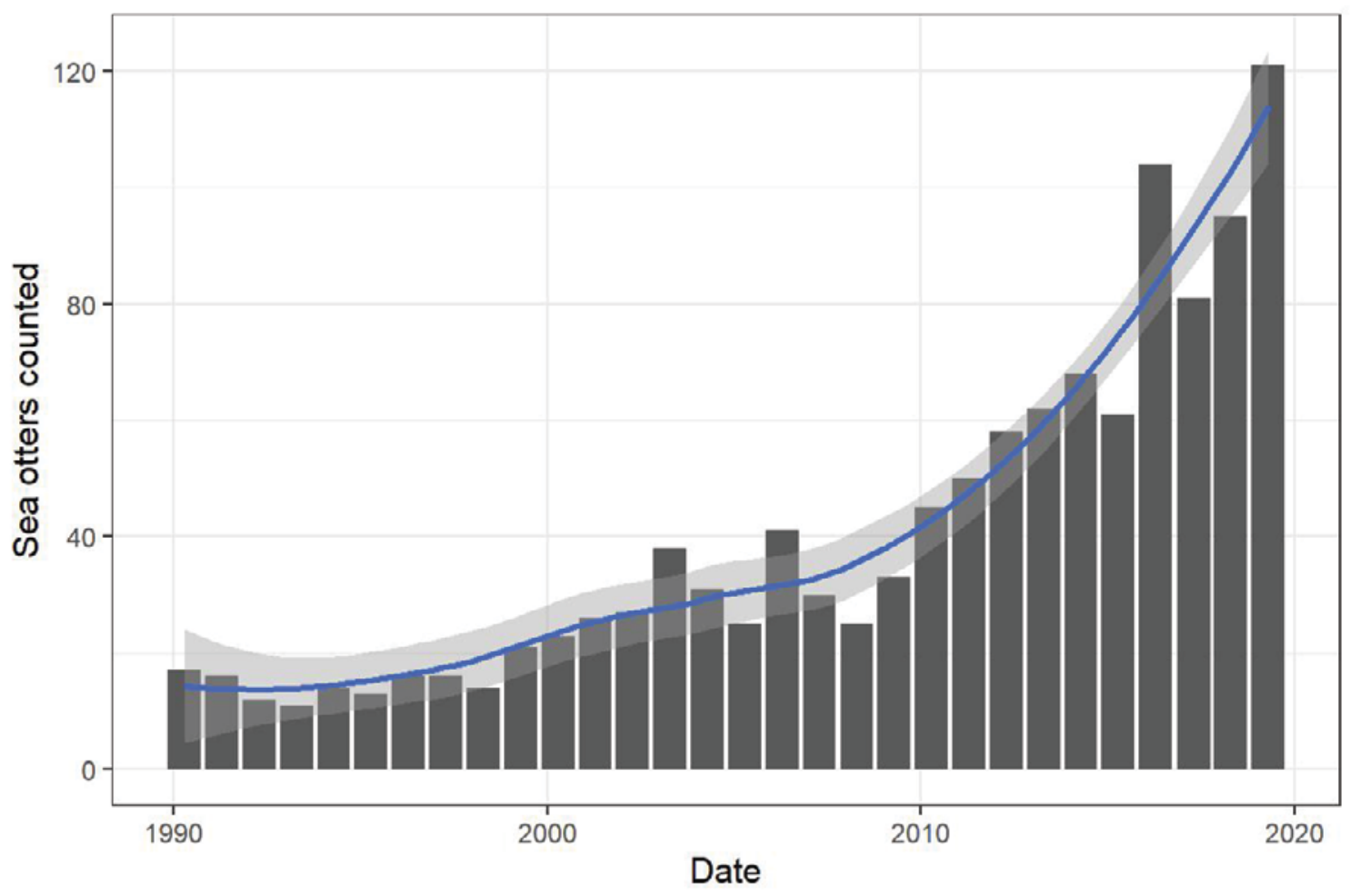

Figure 2. Number of sea otters counted at San Nicolas Island, California, during spring surveys from 1990 to 2019 . Solid line represents a smooth regression of the total sea otter counts in relationship to year, fitted by the locally estimated sum of squares (LOESS) method, and shaded band represents 95-percent confidence intervals around the fitted estimates. 
Table 2. Count of independent sea otters and pups at San Nicolas Island, California, during seasonal surveys from winter 2017 through winter 2020, by area.

\begin{tabular}{|c|c|c|c|c|c|c|c|c|c|c|c|c|c|c|}
\hline \multirow{2}{*}{ Season } & \multirow{2}{*}{ Year } & \multirow{2}{*}{ Month } & \multicolumn{9}{|c|}{ Area count (independents + pups) } & \multicolumn{3}{|c|}{ Island count } \\
\hline & & & 1 & 2 & 3 & 4 & 5 & 6 & 7 & 8 & 9 & Independents & Pups & Total \\
\hline Winter & 2017 & 2 & $2+0$ & $0+0$ & $12+0$ & $9+1$ & $1+0$ & $0+0$ & $1+0$ & $37+6$ & $0+0$ & 62 & 7 & 69 \\
\hline Spring & 2017 & 4 & $3+0$ & $0+0$ & $11+0$ & $20+3$ & $8+0$ & $0+0$ & $13+4$ & $13+2$ & $4+0$ & 72 & 9 & 81 \\
\hline Summer & 2017 & 7 & $10+0$ & $5+0$ & $31+2$ & $5+2$ & $4+0$ & $0+0$ & $0+0$ & $9+4$ & $0+0$ & 64 & 8 & 72 \\
\hline Fall & 2017 & 10 & $36+5$ & $1+0$ & $9+3$ & $6+0$ & $3+0$ & $0+0$ & $1+0$ & $1+0$ & $0+0$ & 57 & 8 & 65 \\
\hline Winter & 2018 & 2 & $30+2$ & $1+0$ & $18+5$ & $19+1$ & $4+0$ & $0+0$ & $1+0$ & $6+0$ & $1+0$ & 80 & 8 & 88 \\
\hline Spring & 2018 & 4 & $12+2$ & $0+0$ & $2+0$ & $31+5$ & $15+0$ & $1+0$ & $2+1$ & $16+6$ & $2+0$ & 81 & 14 & 95 \\
\hline Summer & 2018 & 7 & $12+1$ & $10+0$ & $33+5$ & $5+1$ & $9+0$ & $2+0$ & $1+0$ & $4+0$ & $0+0$ & 76 & 7 & 83 \\
\hline Fall & 2018 & 10 & $22+2$ & $24+0$ & $32+3$ & $10+1$ & $1+0$ & $0+0$ & $2+0$ & $0+0$ & $9+5$ & 100 & 11 & 111 \\
\hline Winter & 2019 & 2 & $8+2$ & $2+1$ & $2+0$ & $18+3$ & $19+0$ & $0+0$ & $3+0$ & $32+11$ & $1+0$ & 85 & 17 & 102 \\
\hline Spring & 2019 & 4 & $20+4$ & $17+1$ & $0+0$ & $23+1$ & $29+0$ & $0+0$ & $8+2$ & $4+1$ & $8+3$ & 109 & 12 & 121 \\
\hline Summer & 2019 & 7 & $32+3$ & $4+0$ & $45+5$ & $9+0$ & $31+3$ & $2+0$ & $6+1$ & $6+0$ & $6+1$ & 141 & 13 & 154 \\
\hline Fall & 2019 & 10 & $29+7$ & $0+0$ & $26+0$ & $4+0$ & $29+1$ & $4+0$ & $6+1$ & $2+0$ & $0+0$ & 100 & 9 & 109 \\
\hline Winter & 2020 & 2 & $2+0$ & $3+0$ & $6+1$ & $37+5$ & $13+1$ & $7+0$ & $11+0$ & $20+4$ & $3+1$ & 102 & 12 & 114 \\
\hline
\end{tabular}

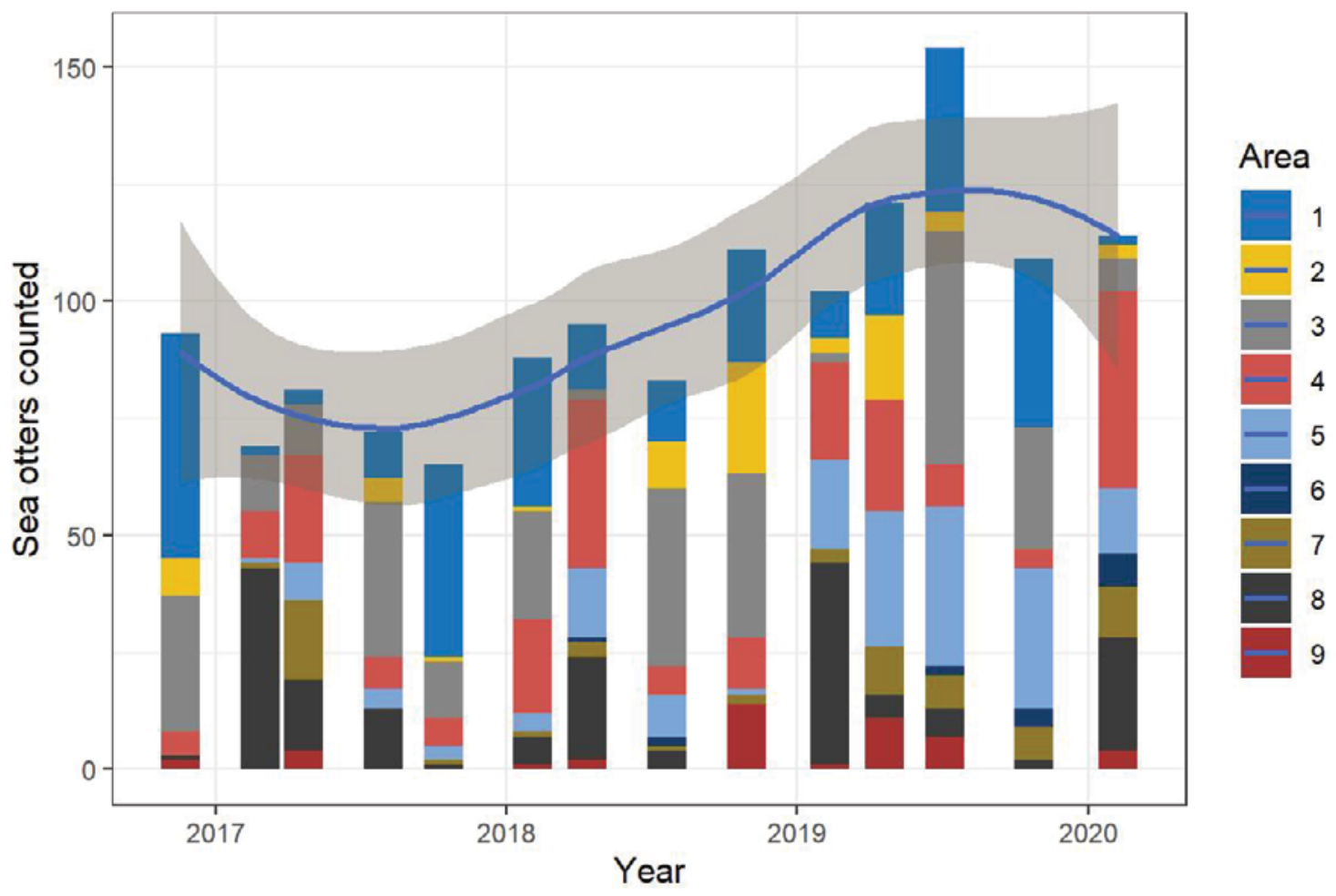

Figure 3. Number of sea otters counted at all 9 areas at San Nicolas Island, California, during 13 seasonal surveys from February 2017 to February 2020. Solid lines represent a smooth regression of the total sea otter counts in relationship to year, fitted by the locally estimated sum of squares (LOESS) method, and shaded band represents 95-percent confidence intervals around the fitted estimates. Sea otter counts from the previous fall survey in 2016 are included for reference. 
The sea otter count, as of the last survey in February 2020, was 114 including independents and pups, and the estimated rate of population growth during the 2017-2020 period is calculated as $\lambda_{2020}=1.22$ (95-percent $\mathrm{CI}=1.11-1.34)$, corresponding to a 22-percent annual growth rate during this period (95-percent $\mathrm{CI}=11-34$ percent). Annual population growth rates varied during the past three decades, with about half of the estimates and 95-percent CI statistically exceeding 1 , representing positive annual growth (fig. 4).

\section{Densities and Distributions}

We compared the densities and distributions of sea otters during spring and fall surveys from the 2017-2019 period with those of the 2014-2016 period, when only spring and fall surveys had been conducted. Sea otter locations were aggregated across the six surveys in each of these 3-year periods to develop kernel density surfaces representing the relative density of cumulative counts (fig. 5). In these maps, sea otter distributions appear to have expanded from concentrations on the west end (areas 1-3) during 2014-2016 surveys toward increased use off the north side (areas 4-6) and the east end (area 7) during 2017-2019, leaving lighter concentrations on the west end. When including all seasonal surveys from fall 2016 through winter 2020, additional hotspots (locations of higher density) become apparent at the northwest and southeast area around Dutch Harbor (area 8; fig. 6).

These maps also display sea otter densities in relationship to kelp canopy images taken during the fall of the years respective to the sea otter surveys. Surface kelp changes significantly over the seasons with the maximum extent typically occurring in the fall. Kelp surveys occurred once annually and were scheduled in the fall with the intent of capturing images of the maximum extent of kelp canopy for that year. Following winter storms, the area of surface kelp is largely reduced and the distribution changes seasonally. Thus, these kelp distributions are not necessarily representative of where kelp beds occurred across the other three seasons when sea otter surveys were conducted, but they are an indicator of where kelp beds are likely to have been present or absent.

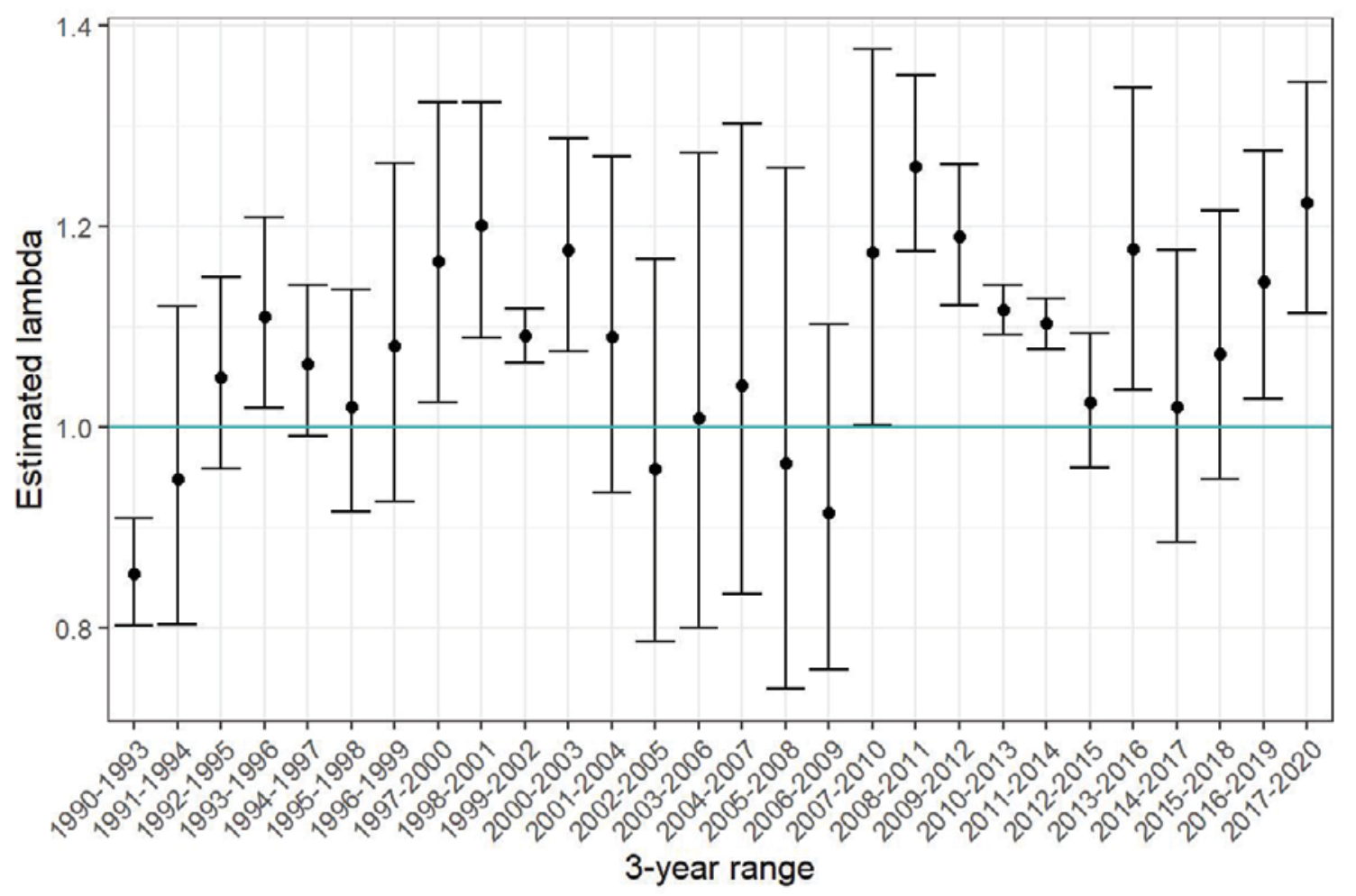

Figure 4. Estimated rates of annual population growth $(\lambda)$ of sea otters at San Nicolas Island, California, over 3-year moving windows from 1990 to 2020, with 95-percent confidence intervals. A value of $\lambda$ that exceeds 1 (blue horizontal line) represents population growth, whereas a $\lambda$ less than 1 represents a population decline. Confidence intervals that overlap with 1 represent insufficient evidence to conclude growth or decline. 
A
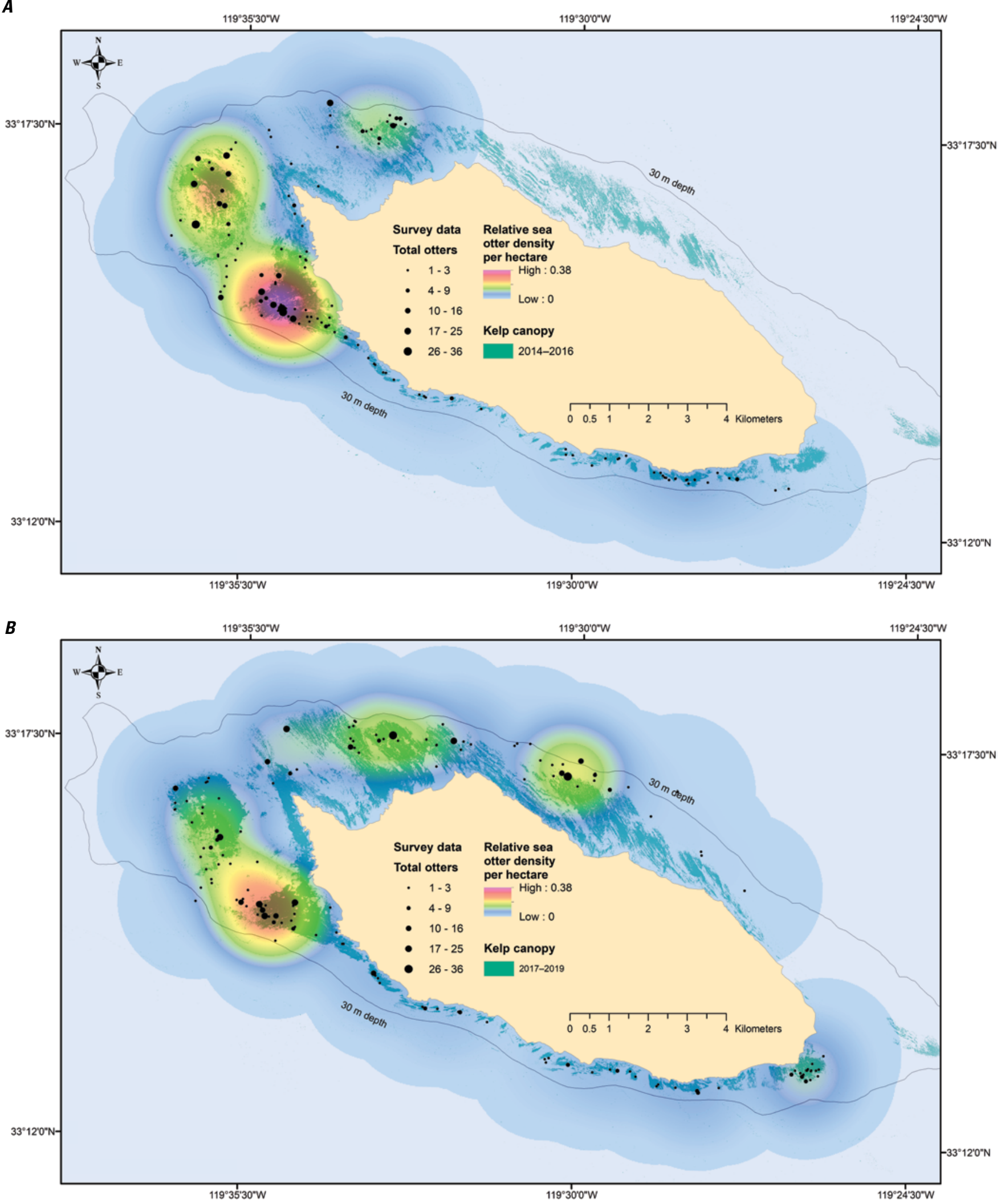

Figure 5. Relative sea otter density during 3 years of fall and spring surveys taken around San Nicolas Island, California, from $A, 2014$ through 2016; and B, 2017 through 2019. Relative densities were spatially modeled using kernel density methods on the cumulative sea otters counted per hectare across six surveys in each comparison period. Kelp canopy images taken during the fall of the 3 respective years are merged and displayed for reference. 


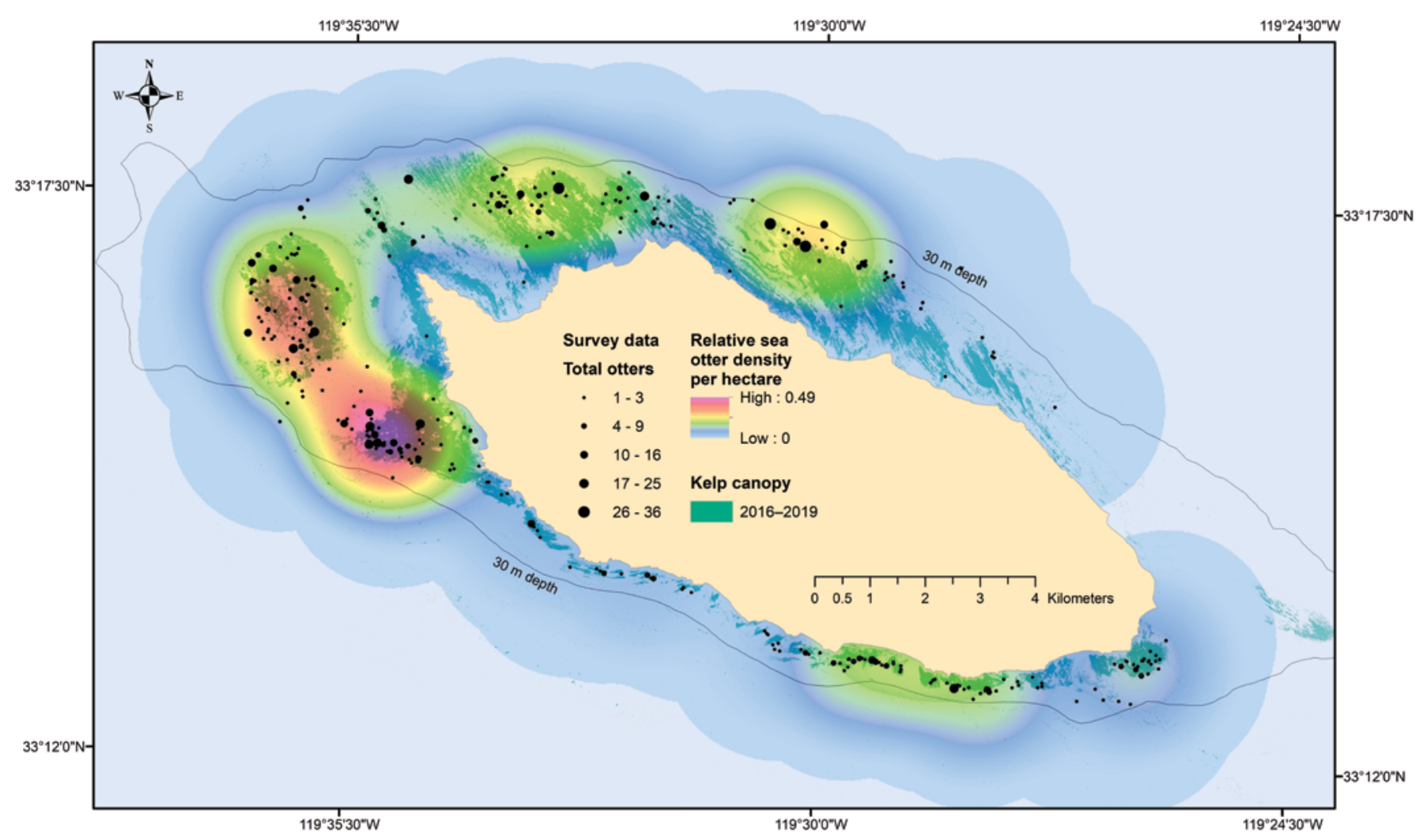

Figure 6. Relative sea otter density during four seasonal surveys combined from 2017 through 2020. Sea otter locations were aggregated across the 14 surveys to develop kernel density surfaces representing the relative density of total counts distributed around San Nicolas Island, California. Kelp canopy images taken during the fall of 2016 through 2019 are merged and displayed for reference.

Radial plots (also known as radar plots) provide a graphical summary of the distribution of sea otters counted around the circumference of the island (Bion, 2020). The nine areas defined in figure 1 are arranged on circular plots in the general cardinal direction as they are oriented around the island (figs. 7, 8). Most of the population distribution tends to concentrate on the west end, specifically at areas 1 and 3 ("The Boilers"), but concentrations have increased on the north side at areas 4 and 5 during the past several years (fig. 7).

Distributions around the island varied seasonally and by year. Areas 1 and 3 ("The Boilers") on the west end have consistently had the most sea otters in the summer and autumn. During the last three surveys, from summer 2019 through winter 2020, areas 4 and 5 combined had a visible spike in sea otter use, starting in area 5 and then shifting more to area 4 (fig. 8). The south side of the island did not have much use except in the winter. Area 6 on the eastern end of the north side, where there is almost no kelp, had very few sea otters in all seasons in all years. The spring season did not reveal obvious patterns in trends, either changes or consistency, over years. Spatial density maps for each of the four seasons reflect these seasonal spatial distribution patterns in greater detail (fig. 9).
To statistically estimate and test seasonal differences in the spatial distribution of sea otters generally, we aggregated sea otter counts among the north side, south side, and west end (fig. 1). We found significant differences in distribution among sides between year $\left(\chi_{2}^{2}=6.15, p=0.046\right)$ and season $\left(\chi_{6}^{2}=33.77, p<0.001\right)$, but no evidence of interaction effects between year and season $\left(\chi_{6}^{2}=4.49, p=0.610\right)$. Concentrations on the west side increased in the summer and peaked around summer or autumn before decreasing to minimal use around winter or spring (fig. 10). Distributions increased on the north and south sides during this period, with most of the increases in the north occurring in the spring and most of the increases in the south occurring in the winter. The shift from west end to north and south sides occurred between fall and winter (November and February) in three of the last four fall-winter periods (2016-2017, 2018-2019, and 2019-2020) while, in contrast, for the fall 2017-winter 2018 period, the shift appeared to start later toward the spring. Overall, the seasonal duration of use of the north side appears to have gradually increased during the 2017-2020 reporting period. 


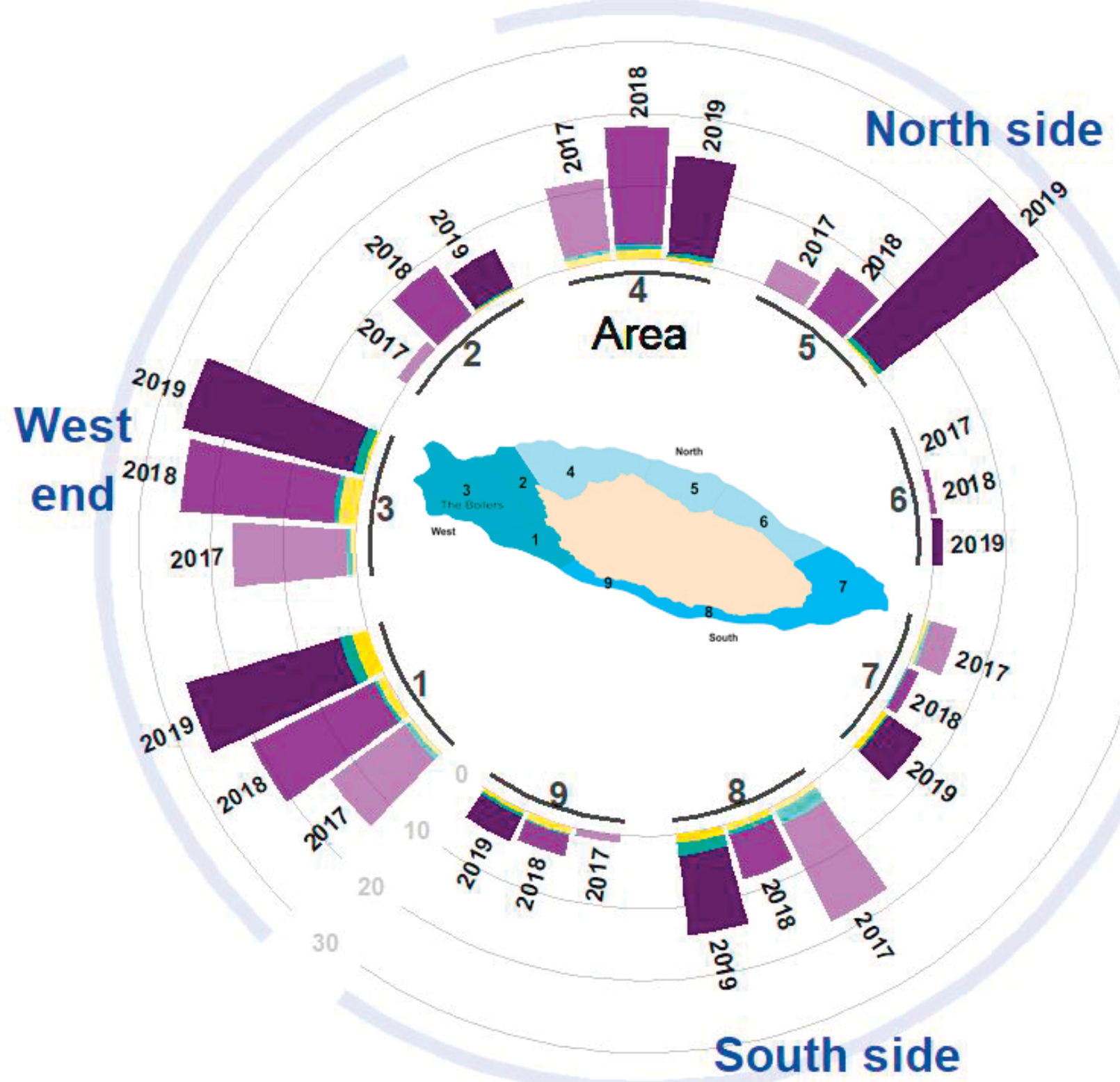

Figure 7. Average number of sea otters counted per year (2017-2019) at nine survey areas (see map inset for locations of numbered areas) around San Nicolas Island, California. Bars are color coded by area (purple=adults, green=large pups, and yellow=small pups), and shades darken with later years (2017 is lightest, and 2019 is darkest). 2020 is omitted because of insufficient data to calculate comparable annual averages. Areas 1, 2, and 3 ("The Boilers") represent the west end of the island; areas 4, 5, and 6 represent the north side; and areas 7,8 , and 9 represent the south side. 


\section{Winter}
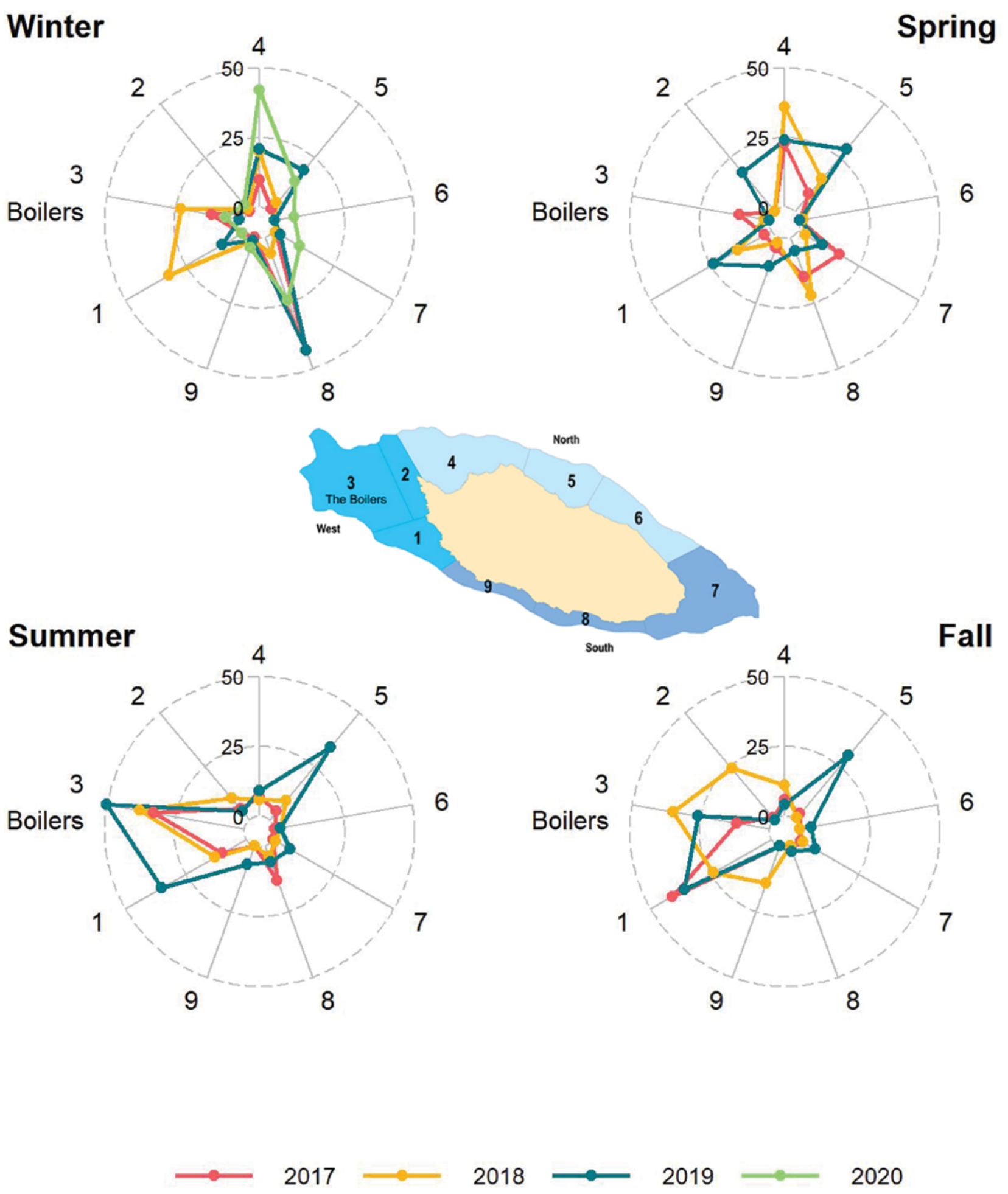

Figure 8. The abundance of sea otters around the periphery of San Nicolas Island, California, by season (winter, spring, summer, and fall), 2017-2020. Each plot displays the number of sea otters counted at nine areas (see map inset for locations of numbered areas) around the island on the high-count date of each seasonal survey, for each year. Concentric circles represent a minimum count of 0 sea otters (inner circle), a maximum count of 50 (outer circle), and a middle value of 25. 


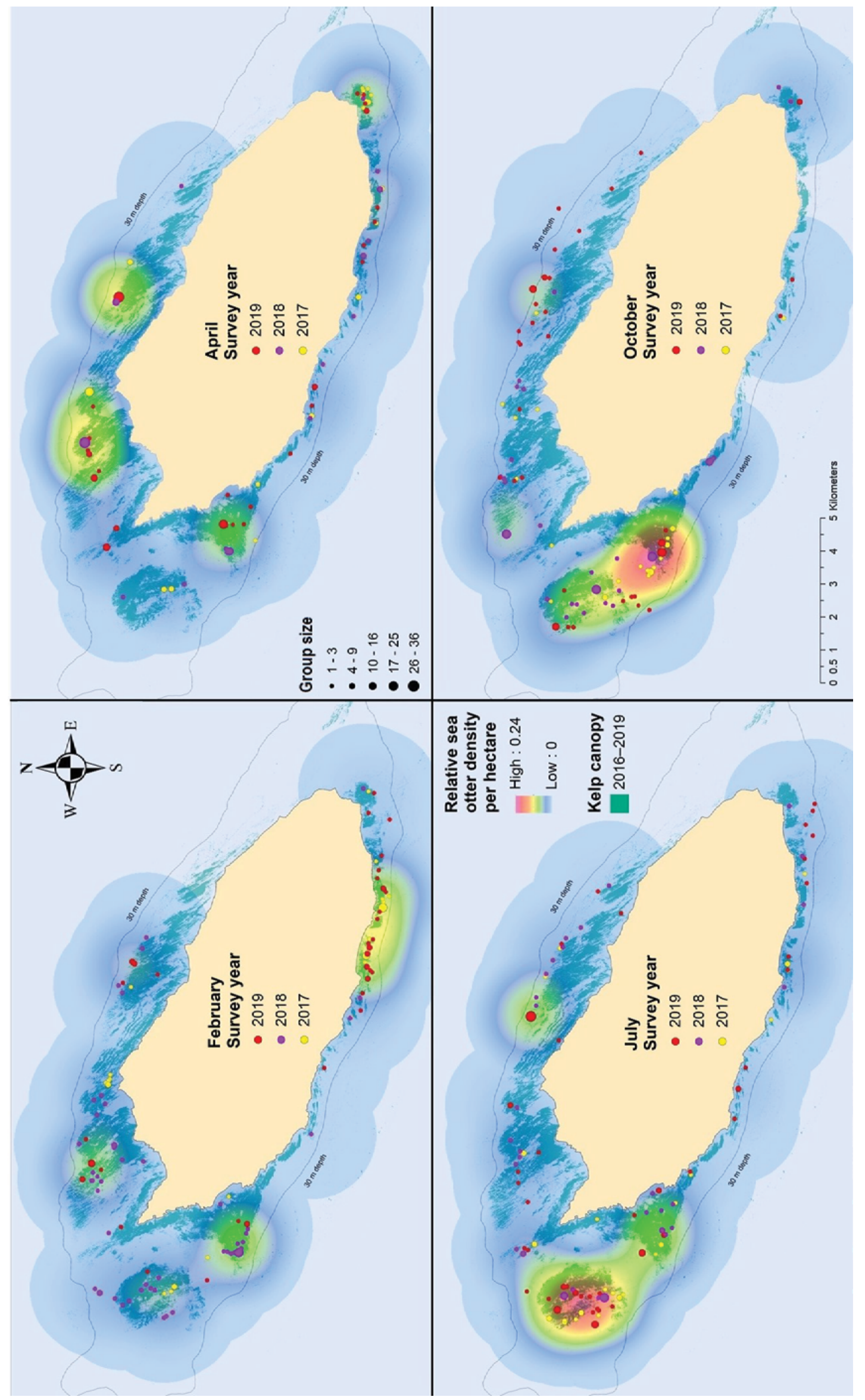

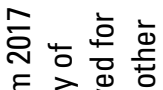

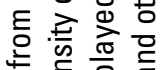

드응 중

षे 음

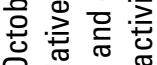

은ㅎㅀ 월

元 ఖ

둥이

든 은 뭉

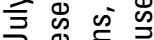

는

है

空

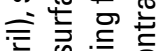

훙 क

잉 齐

흔흥

के ब के

文热

올 응 중

항 응 要

는

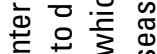

3 os:

$\cong$ ฏ

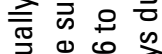

릴일

वे है

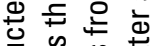

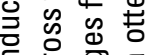

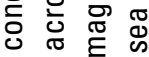

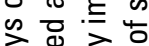

बे

के क्ष

임욤을

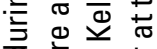

㐫

के के

흥 음 놇 흥

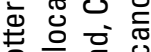

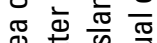

क

0 舫

車舟

뜬

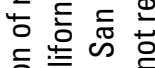

을 恶

卷它言

些要需

西要

엉 을

步 $\frac{0}{2}$

क

额 売

o के ठ⿹

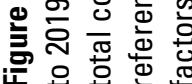




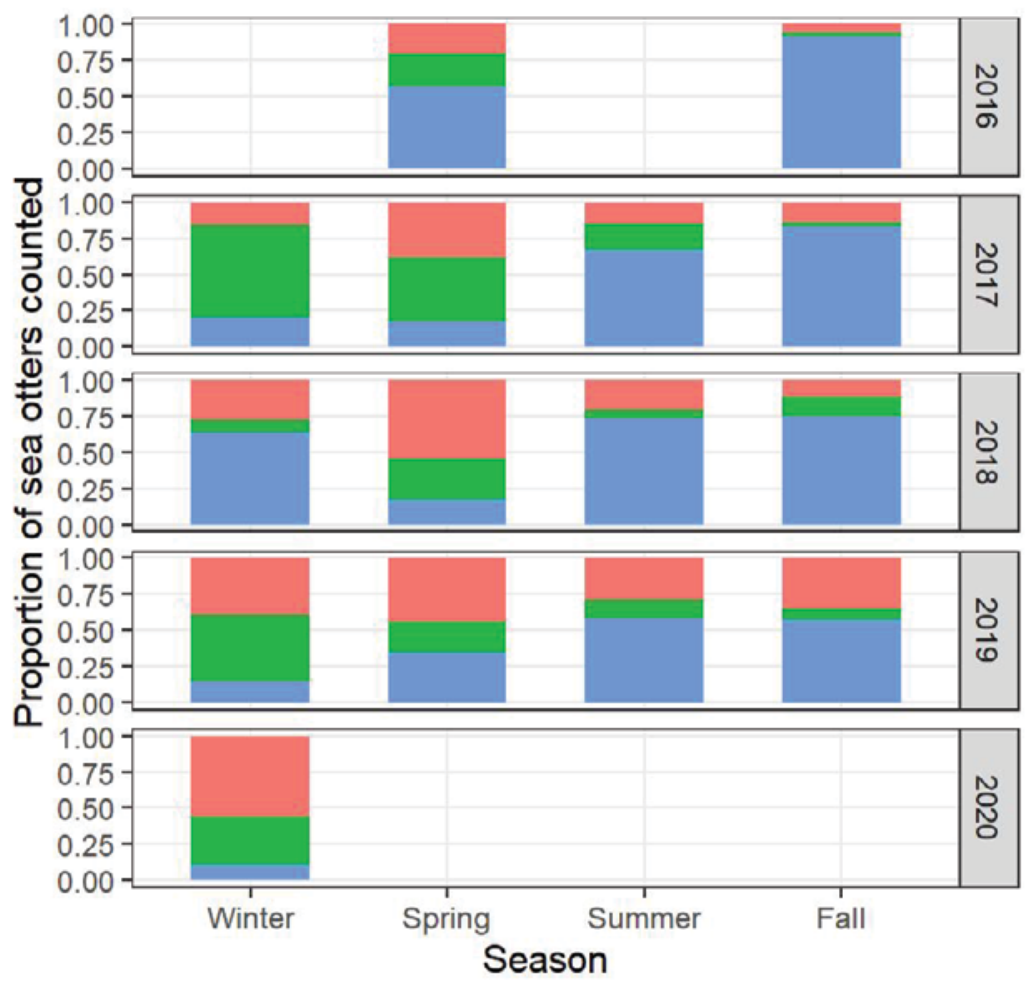

North side (Areas 4-6) South side (Areas 7-9)

West end (Areas 1-3)

Figure 10. Distribution of sea otters among three sections (north side, south side, and west end) around San Nicolas Island, California, for seasonal surveys (winter, spring, summer, and fall) done from winter 2017 through winter 2020. Spring and fall distributions from previous semiannual surveys in 2016 are included for reference.

\section{Foraging}

Foraging data were collected opportunistically as time and viewing conditions allowed. As a result, the numbers of foraging observations varied by survey and location. A total of 167 sea otter foraging bouts were observed from winter 2017 through winter 2020, for a total of 2,675 diving observations distributed in groups of 42-364 diving observations per survey trip (tables 3, 4). More than 700 diving observations were collected every year from 2017 through 2019, but surveys were suspended in 2020 due to the COVID-19 pandemic and only 94 diving observations were collected. Most foraging bouts were recorded on the west end and south side (36.5 and 34.7 percent, respectively) compared to the north side (10.2 percent). Among all dives, 1,633 were observed on 89 female foraging bouts, 504 were observed on 29 male foraging bouts, and the remaining 538 were observed on 49 foraging bouts of unknown sex.
We classified identifiable prey species into taxonomic groups based on prevalence in the diet (urchins, snails, crabs) or energetic content of less prevalent prey species (abalone, lobsters, octopus), and lumped all other species (other). Thirty percent of successful dives $(570$ of 1,905$)$ observed during 2017-2020 resulted in unidentified prey items (table 5). We used Monte-Carlo simulations to estimate the likely caloric values of unidentified prey based on partial data about the prey, such as their size and the lowest taxonomic level to which they could be identified. These simulations use empirical information about the likelihood of different prey species and the associated caloric values for their size class, based on the frequency with which specific species and sizes were identified in the data. This process enabled us to derive 95-percent confidence intervals to account for prey uncertainty. Because these simulations require robust sample sizes to provide sufficient information on prey, we aggregated data into large groups and calculated energy rates for all observations combined and separately by year (except 2020 due to low sample size), by season, and by sex. 
Table 3. Number of foraging bouts surveyed by season, sex, age class, and section of San Nicolas Island, California, 2017-2020, summarized by year and for all years combined.

[Four seasonal surveys occurred every year except in 2020 when surveys were suspended starting in spring.]

\begin{tabular}{|c|c|c|c|c|c|}
\hline & \multicolumn{4}{|c|}{ Year } & \multirow{2}{*}{$\begin{array}{c}\text { All } \\
\text { years }\end{array}$} \\
\hline & 2017 & 2018 & 2019 & 12020 & \\
\hline Total foraging bouts & 44 & 51 & 62 & 10 & 167 \\
\hline \multicolumn{6}{|c|}{ Season } \\
\hline Winter & 13 & 16 & 24 & 10 & 63 \\
\hline Spring & 3 & 10 & 12 & 0 & 25 \\
\hline Summer & 8 & 17 & 11 & 0 & 36 \\
\hline Fall & 20 & 8 & 15 & 0 & 43 \\
\hline \multicolumn{6}{|c|}{ Sex } \\
\hline Females & 28 & 18 & 39 & 4 & 89 \\
\hline Males & 7 & 14 & 7 & 1 & 29 \\
\hline Unknown sex & 9 & 19 & 16 & 5 & 49 \\
\hline \multicolumn{6}{|c|}{ Age class } \\
\hline Adults & 33 & 39 & 54 & 9 & 135 \\
\hline Aged adults & 2 & 0 & 0 & 0 & 2 \\
\hline Sub-adults & 3 & 7 & 6 & 1 & 17 \\
\hline Juveniles & 1 & 2 & 0 & 0 & 3 \\
\hline Unknown age & 5 & 3 & 2 & 0 & 10 \\
\hline \multicolumn{6}{|c|}{ Location } \\
\hline North side & 4 & 8 & 3 & 2 & 17 \\
\hline South side & 8 & 6 & 36 & 8 & 58 \\
\hline West end & 20 & 23 & 18 & 0 & 61 \\
\hline Unrecorded location & 12 & 14 & 5 & 0 & 31 \\
\hline
\end{tabular}

${ }^{1}$ Surveys were suspended after the winter 2020 survey due to the Coronavirus disease of 2019 (COVID-19) pandemic and no foraging data were obtained during the remainder of the year.
Table 4. Number of foraging dives observed by season and sex, and diving outcomes at San Nicolas Island, California, 2017-2020, summarized by year and for all years combined.

[Four seasonal surveys occurred every year except in 2020 when surveys were suspended starting in spring.]

\begin{tabular}{|c|c|c|c|c|c|}
\hline & \multicolumn{4}{|c|}{ Year } & \multirow{2}{*}{$\begin{array}{c}\text { All } \\
\text { years }\end{array}$} \\
\hline & 2017 & 2018 & 2019 & 12020 & \\
\hline Foraging dives & 731 & 887 & 963 & 94 & 2,675 \\
\hline \multicolumn{6}{|c|}{ Season } \\
\hline Winter & 208 & 262 & 343 & 94 & 907 \\
\hline Spring & 42 & 231 & 237 & 0 & 510 \\
\hline Summer & 117 & 262 & 147 & 0 & 526 \\
\hline Fall & 364 & 132 & 236 & 0 & 732 \\
\hline \multicolumn{6}{|c|}{ Sex } \\
\hline Females & 506 & 429 & 658 & 40 & 1,633 \\
\hline Males & 157 & 226 & 104 & 17 & 504 \\
\hline Unknown sex & 68 & 232 & 201 & 37 & 538 \\
\hline \multicolumn{6}{|c|}{ Outcomes } \\
\hline Successful dives & 553 & 562 & 704 & 86 & 1,905 \\
\hline Unsuccessful dives & 125 & 218 & 204 & 5 & 552 \\
\hline 2Other & 33 & 50 & 26 & 3 & 112 \\
\hline Unknown outcomes & 20 & 57 & 29 & 0 & 106 \\
\hline Known outcomes & 711 & 830 & 934 & 94 & 2,569 \\
\hline Known success or unsuccess & 678 & 780 & 908 & 91 & 2,457 \\
\hline $\begin{array}{l}\text { Percentage success rate } \\
\text { (successes/dives) }\end{array}$ & 81.6 & 72.1 & 77.5 & 94.5 & 77.5 \\
\hline Mean dives per bout & 16.6 & 17.4 & 15.5 & 9.4 & 16 \\
\hline $\begin{array}{l}\text { Mean diving duration } \\
\text { (seconds) }\end{array}$ & 49.8 & 58.1 & 61.6 & 63.3 & 57.2 \\
\hline $\begin{array}{l}\text { Mean surface interval } \\
\text { (seconds) }\end{array}$ & 45.1 & 46.8 & 49.5 & 57.5 & 47.7 \\
\hline
\end{tabular}

${ }^{1}$ Surveys were suspended after the winter 2020 survey due to the Coronavirus disease of 2019 (COVID-19) pandemic and no foraging data were obtained during the remainder of the year.

${ }^{2}$ Dives in which sea otters carried prey from the previous dive or took prey from another sea otter were considered neither successful nor unsuccessful. 
Table 5. Number of successful dives with prey categorized into seven prey classes observed during two periods of foraging surveys at San Nicolas Island, California, 2003-2006 and 2017-2020.

[Data from the 2003-2006 period were obtained from historical records of a similar foraging study previous to the current study in the $2017-2020$ period.]

\begin{tabular}{lrrrrrrrr}
\hline \multirow{2}{*}{ Prey class } & \multicolumn{7}{c}{ Year } \\
\cline { 2 - 9 } & $\mathbf{2 0 0 3}$ & $\mathbf{2 0 0 4}$ & $\mathbf{2 0 0 5}$ & $\mathbf{2 0 0 6}$ & $\mathbf{2 0 1 7}$ & $\mathbf{2 0 1 8}$ & $\mathbf{2 0 1 9}$ & $\mathbf{2 0 2 0}$ \\
\hline Abalone & 3 & 3 & 0 & 0 & 0 & 2 & 3 & 0 \\
Crabs & 131 & 386 & 16 & 20 & 31 & 12 & 33 & 2 \\
Lobsters & 1 & 7 & 0 & 0 & 6 & 13 & 7 & 0 \\
Octopus & 0 & 5 & 0 & 0 & 5 & 8 & 3 & 0 \\
Snails & 28 & 192 & 35 & 7 & 92 & 30 & 109 & 9 \\
Sea urchins & 154 & 982 & 33 & 109 & 292 & 336 & 270 & 42 \\
Other & 7 & 10 & 0 & 2 & 5 & 5 & 20 & 0 \\
Unidentified & 87 & 340 & 11 & 2 & 122 & 156 & 259 & 33 \\
Total & 411 & 1,925 & 95 & 140 & 553 & 562 & 704 & 86 \\
\hline
\end{tabular}

Sea urchins, including the red sea urchin (Strongylocentrotus franciscanus) and purple sea urchin (S. purpuratus), composed the majority (about two thirds) of prey types among all successful diving outcomes, with the remaining successful diving outcomes comprised mostly of snails followed by crabs (figs. 11-14). Simulated estimates of energy intake rates averaged $17.3 \mathrm{kcal} / \mathrm{min}$ (95-percent $C I=15.6-19.0)$ and, when calculated separately by groups, suggest potential differences among years, seasons, and sexes (figs. 11, 13, 14). These calculations suggest potential temporal effects, including annual declines in energy intake estimates from 2017 to 2019 and seasonally higher energy intake estimates in the winter and spring compared to the summer and fall, and that identified females and males had higher energy intake estimates than sea otters of unidentified sex. However, due to the percentage of unidentified prey and the limited amount of identified data, the 95-percent confidence intervals for these rates are relatively large compared to the estimated differences, and many of these confidence intervals overlap. Thus, prey uncertainty along with survey sampling variations can contribute some degree of errors to these apparent differences.
Nevertheless, sampling uncertainties do not negate the likelihood for real changes to occur. Because of the possible decline in energy intake rates during the 2017-2019 period, we examined the composition of sea urchin species, the prey group comprising the majority of successful sea otter forage diving outcomes. Red sea urchins generally are larger (median diameter $=53 \mathrm{~mm}$, interquartile range [IQR; 25-75-percentile] $=41-65 \mathrm{~mm}$ ), have higher caloric value, and are preferred by sea otters compared to purple sea urchins (median diameter $=28 \mathrm{~mm}, \mathrm{IQR}=21-36 \mathrm{~mm}$; Kenner and Tomoleoni, 2020). Changes in the ratio of red to purple sea urchins may correlate with prey availability. We inspected this ratio during the 2017-2020 period and compared it to ratios from 2003 to 2006 when similar sea otter foraging surveys were conducted at SNI. Between 33 and 982 sea urchins were identified each year (table 5), and these data indicated a decreasing trend in the ratio of red to purple sea urchins, which suggests that a decrease in the availability of this important prey species has likely occurred (fig. 12). 


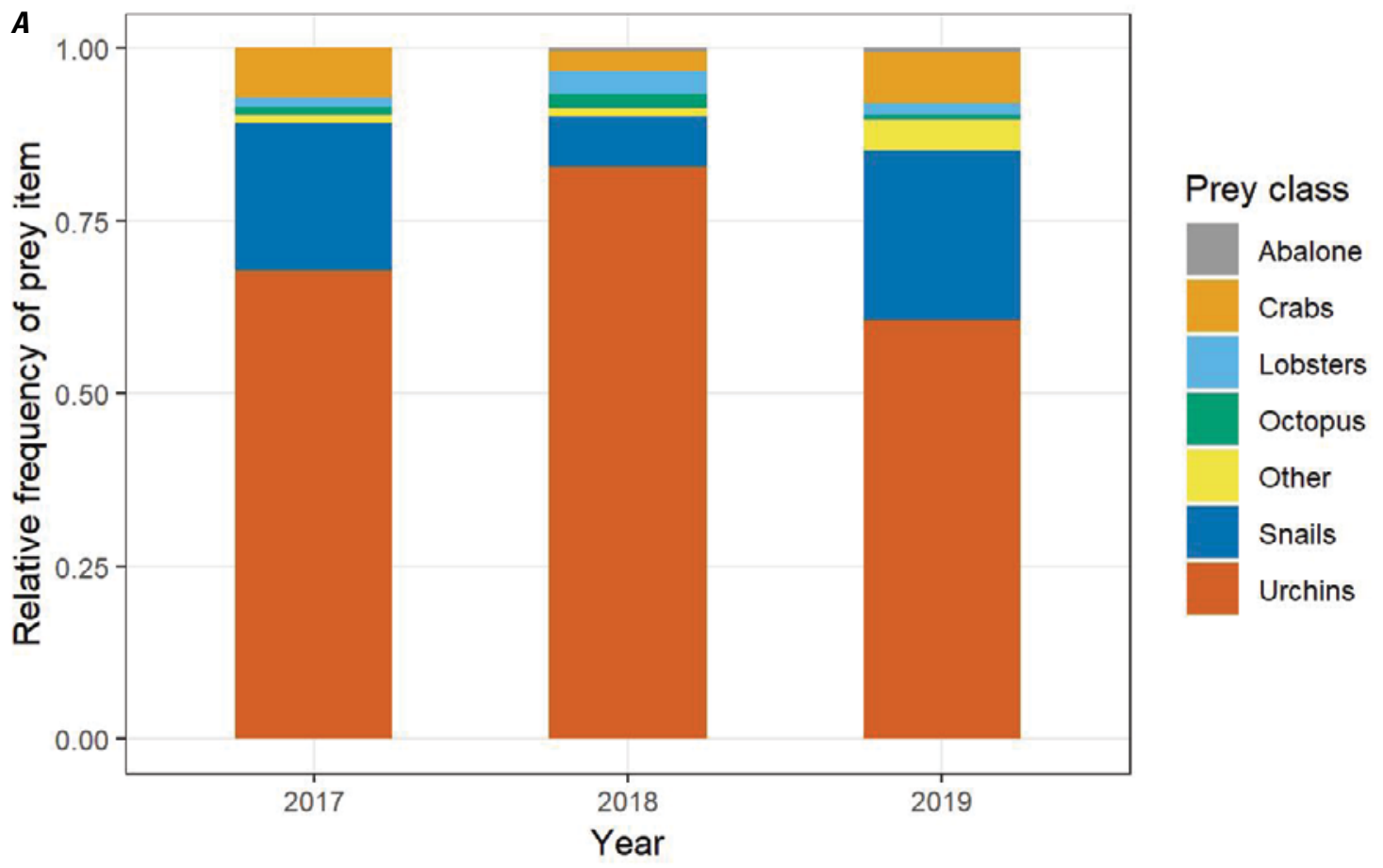

B

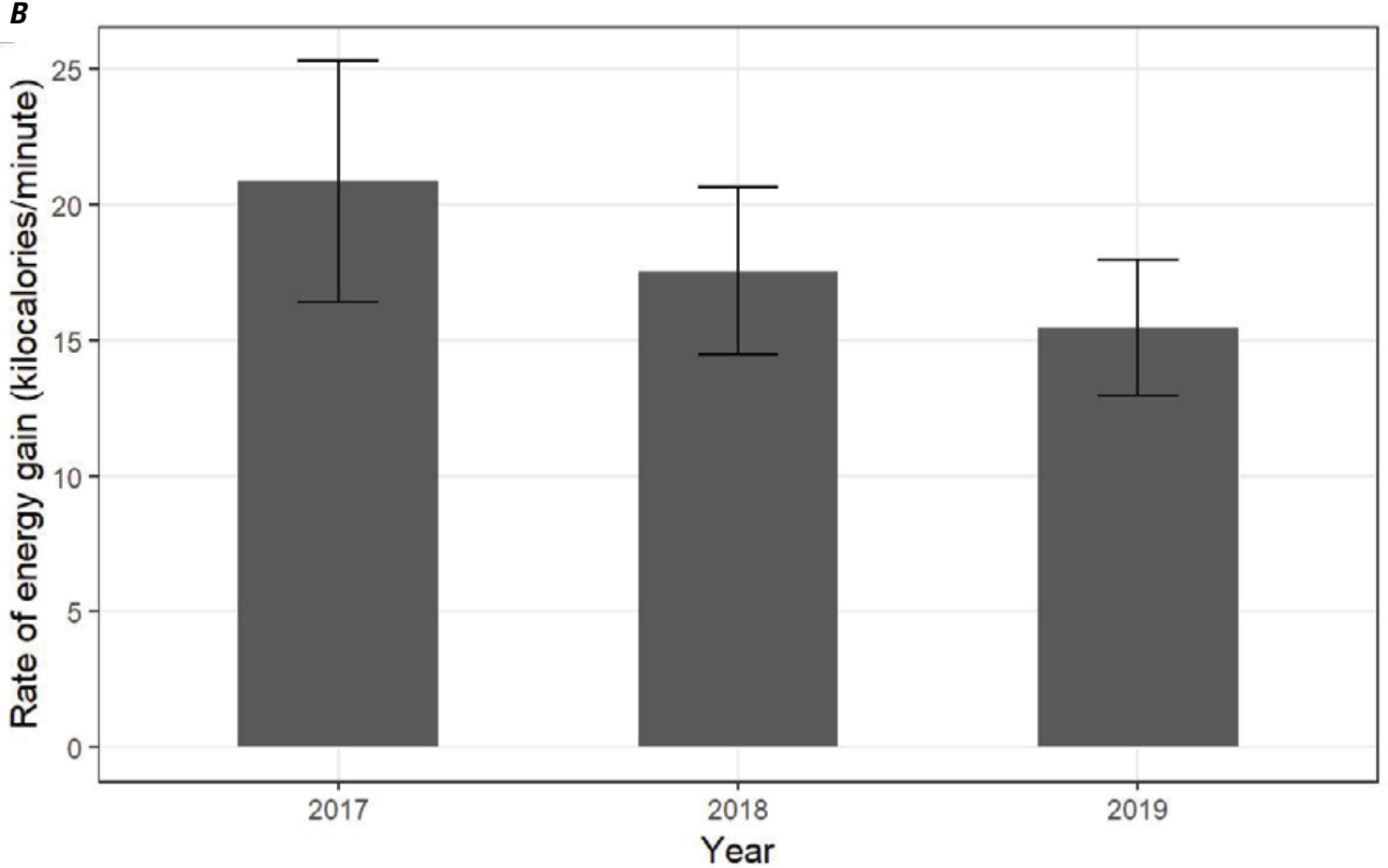

Figure 11. Foraging outcomes of sea otters by year, including $A$, relative frequency at which prey items were observed and identified; and $B$, rate of energy gain (kilocalories per minute [kilocalories/minute], with 95-percent confidence interval), at San Nicolas Island, California, 2017-2019. Foraging rates were not estimated for 2020 due to insufficient data. 


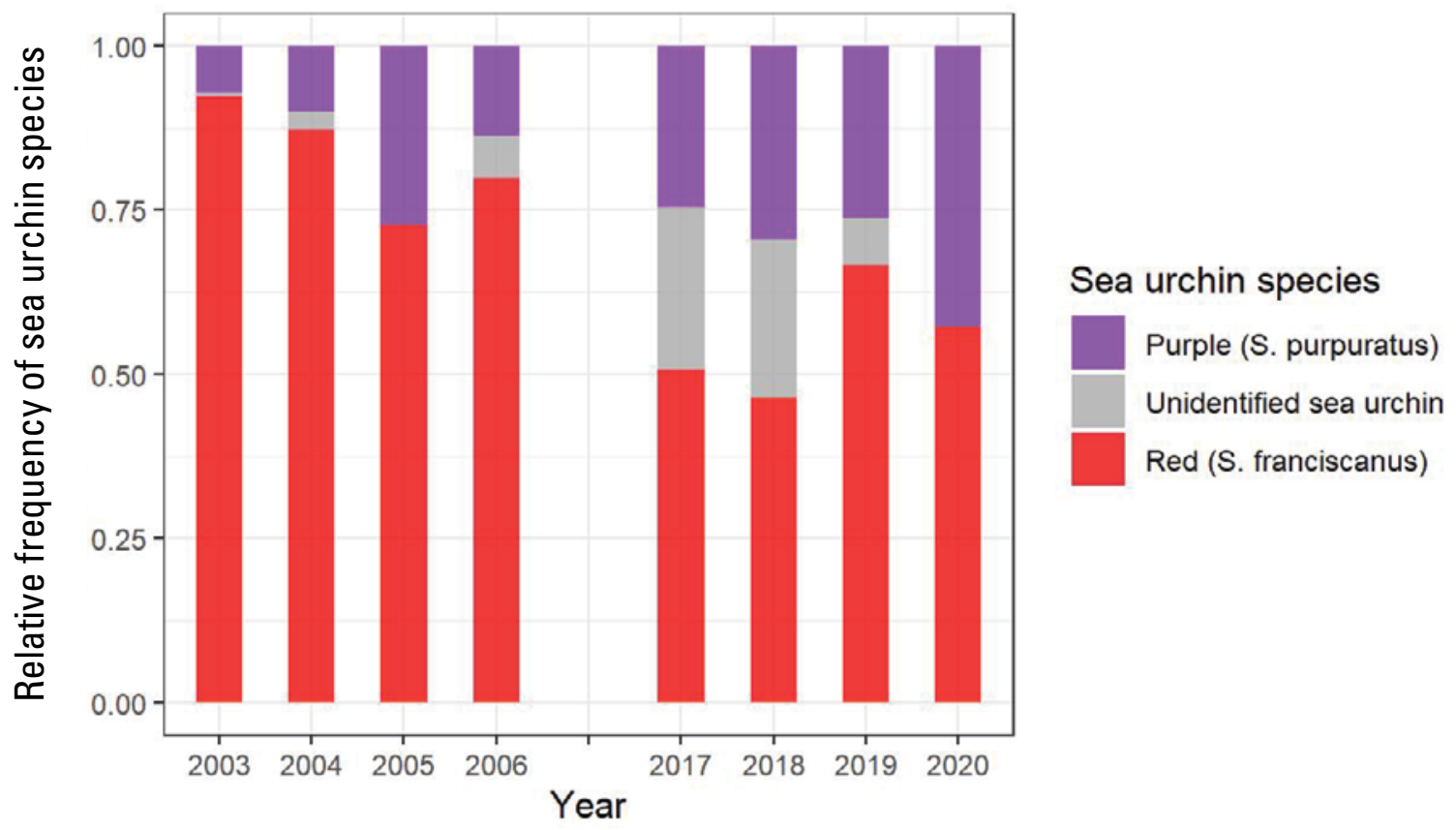

Figure 12. Relative frequency at which different species of sea urchins (Strongylocentrotus) were observed in sea otter diets during two periods of foraging surveys at San Nicolas Island, California, 2003-2006 and 2017-2020. 


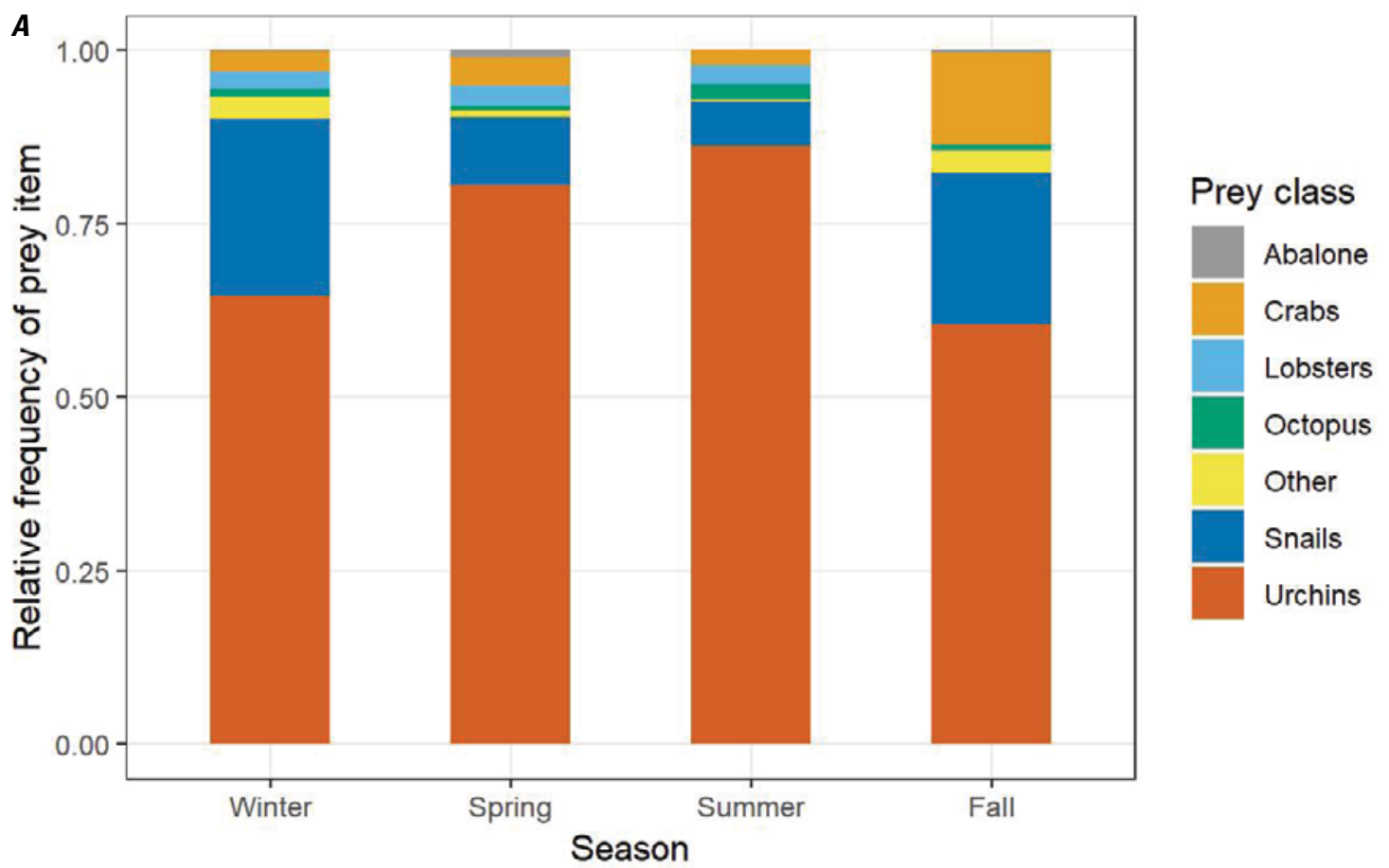

B

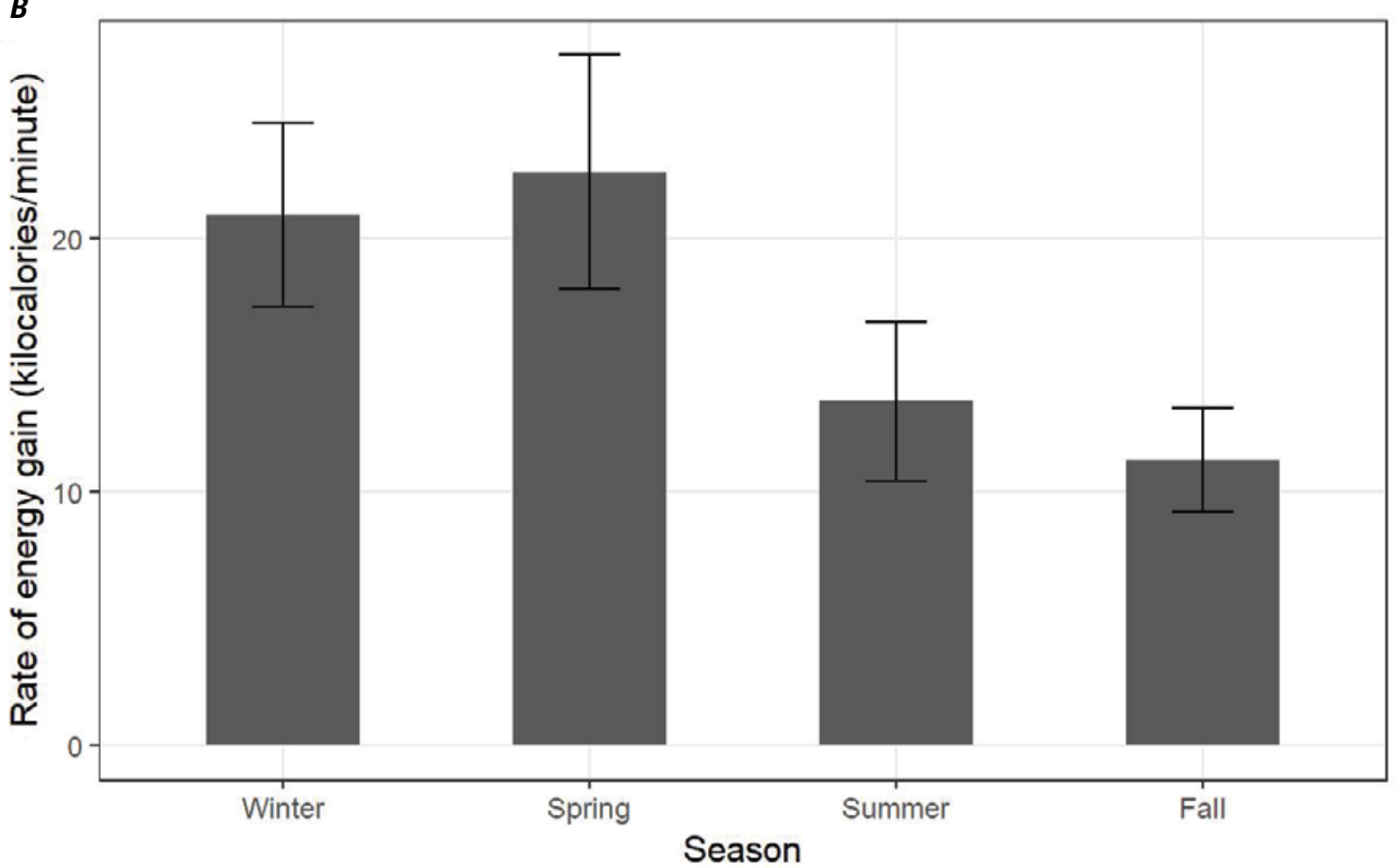

Figure 13. Foraging outcomes of sea otters by season, including $A$, relative frequency at which prey items were observed and identified; and $B$, rate of energy gain (kilocalories per minute, with 95-percent confidence interval), at San Nicolas Island, California, 2017-2020. 

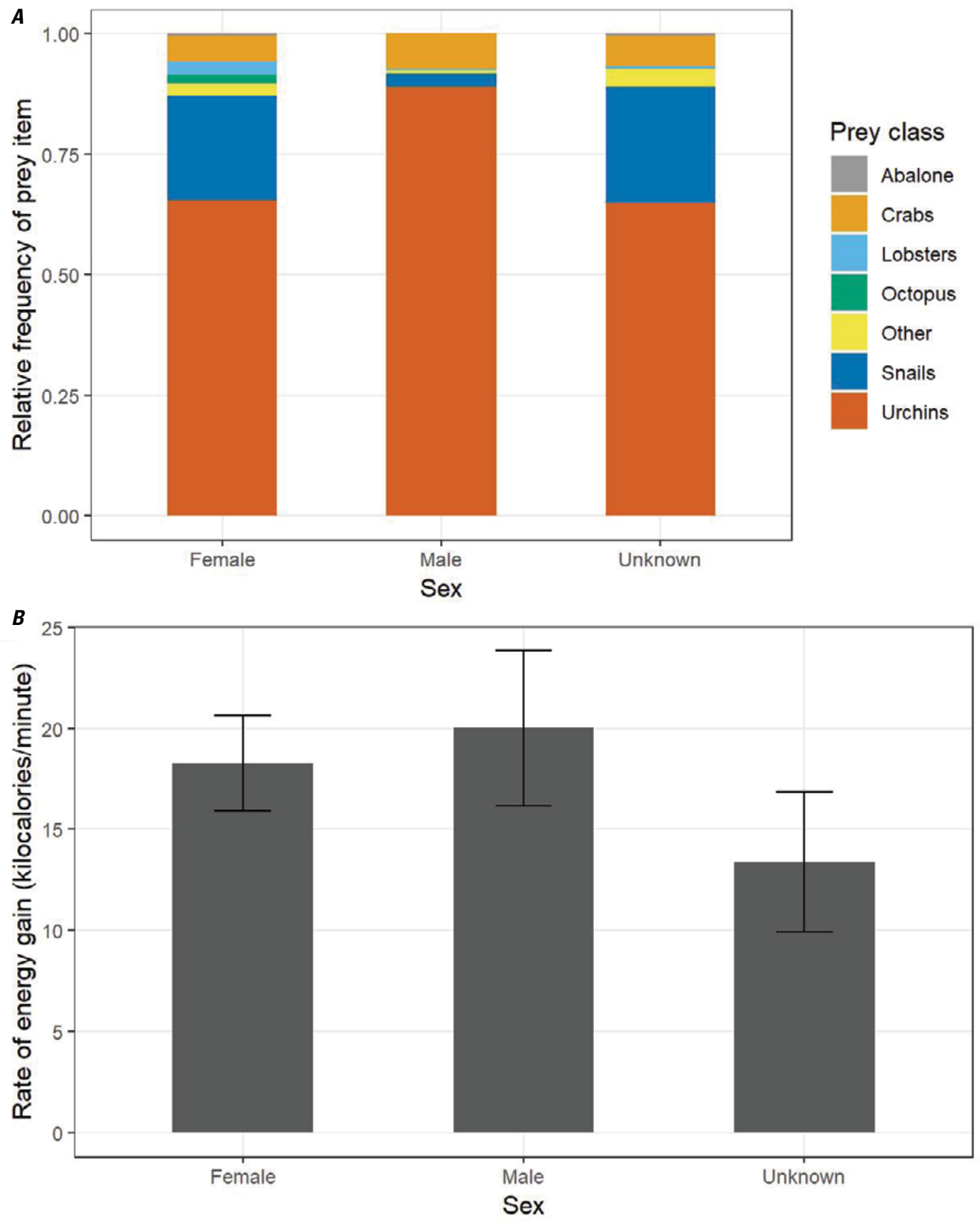

Figure 14. Foraging outcomes of sea otters by sex (female, male, unknown), including $A$, relative frequency at which prey items were observed and identified; and $B$, rate of energy gain (kilocalories per minute [kilocalories/minute], with 95-percent confidence interval), at San Nicolas Island, California, 2017-2020. 


\section{Precision and Power}

Because the estimated population growth rate during the most recent 3-year interval (2017-2020) was calculated as $\lambda_{2020}=1.22$, then a 10-percent decrease in this trend rate would be $\lambda=0.9 \times 1.22=1.10$, in other words, where a 22-percent annual growth rate decreases to a 10-percent annual growth rate. We simulated sea otter count data for 2021 and 2022 based on a range of $\lambda$ from 0.90 to 1.10 , in other words, from a 10-percent annual reduction to a 10-percent annual growth to determine the precision and power of one to four surveys per year in detecting that $\lambda$ is less than 1.10 in the next two 3-year moving intervals, 2018-2021 and 2019-2022. The simulated reductions in $\lambda$ during 2021-2022 introduced more variations in sea otter counts around its trend in 2018-2021 and 2019-2022 than if $\lambda$ were to remain unchanged. As a result, our simulations produced higher CV as $\lambda$ decreased and when both simulated years were included for the 2019-2022 trend compared to one simulated year for the 2018-2021 trend (fig. 15). These simulations also demonstrate increases in $\mathrm{CV}$, and hence decreases in precision, as the number of surveys per year decreases. The $\mathrm{CV}$ ranged from 0.020 to 0.027 for four surveys per year, $0.024-0.031$ for two surveys per year, and $0.029-0.038$ for one survey per year, with actual $\mathrm{CV}$ depending on the decrease in $\lambda(0.90$ to $1.10)$ and on the interval (2018-2021 or 2019-2022). These ranges corresponded to a 14-25 percent increase in CV when reducing the number of surveys by half (for example, from 4 to 2 , or from 2 to 1 ).

Our simulations also demonstrate that the statistical power of detecting greater than 10-percent reductions in the population trend rate $\lambda$ increases with the extent of the reduction, the years of monitoring that reduction, and the number of surveys per year (fig. 16). The power to detect a greater than 10-percent reduction during 2018-2021 differed considerably among levels of survey effort when $\lambda$ was reduced to $1: 0.12$ for one survey per year, 0.52 for two surveys per year, 0.76 for three surveys per year, and 0.88 for four surveys per year. For the largest and the smallest reductions that we simulated, in other words, $\lambda=0.90$ and 1.10 respectively, there was somewhat less of a difference in power between two and four surveys per year. When $\lambda$ is reduced to just under 1.10, there is relatively low power in detecting that $\lambda$ is less than 1.10 because, although the estimated rate $\lambda$ is likely to be near or below 1.10 , the variation in data and uncertainty around the estimate can result in an upper confidence limit that exceeds 1.10 . When $\lambda$ is reduced to 0.90 , there also is very little difference in power between two and four surveys per year because such a large decline in rates is very detectable given the typical variation in data. As a result, the number of surveys has greater influence on the power to detect reductions in growth when the reduction is moderately below the threshold of interest (in this case 1.10), compared to immediately below or farther below the threshold (for example, 0.90).

Because the military readiness area monitoring and research plan specifies that part of the trigger for a higher tier of monitoring research is "at least 2 consecutive years" of a greater than 10-percent decrease in the population trend rate, we used our simulation outcomes to calculate the probability of detecting this decrease in both the 2018-2021 and the 2019-2022 intervals. We found that when the decrease is detected in the 2018-2021 interval, then it is generally detected in the 2019-2022 interval also, but not vice versa. As such, the power of detecting the decrease in both intervals is essentially equivalent to the power of detecting the decrease in the first interval (fig. 16).

We did not conduct precision and power analyses on foraging data because the Monte Carlo iterations required to perform foraging analyses on the current dataset is time-intensive, taking one workday to process. A simulation study to estimate the precision and power of our foraging analysis would compound this time by thousands. Furthermore, the smaller the number of foraging observations, then the greater the uncertainty in the estimates, and the more iterations required for each foraging analysis to converge. Each foraging rate estimate typically requires at least 300 foraging observations and 50 foraging bouts, which are very difficult sample sizes to acquire in 3 or fewer survey trips but can be accomplished with 4 surveys. The foraging analysis becomes more accurate as more foraging observations are collected. 


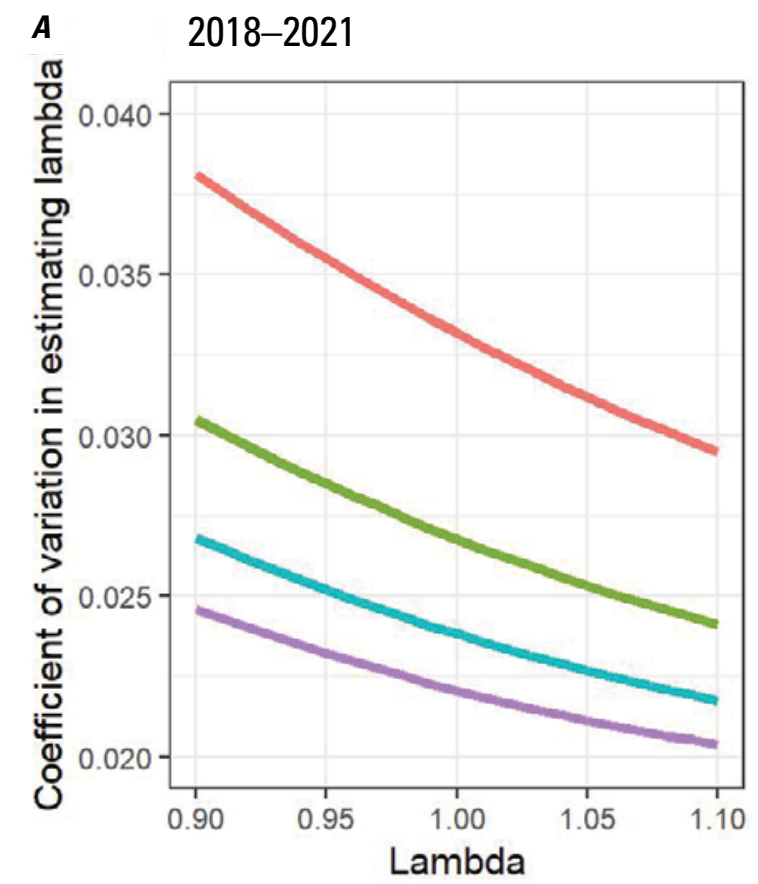

B 2019-2022

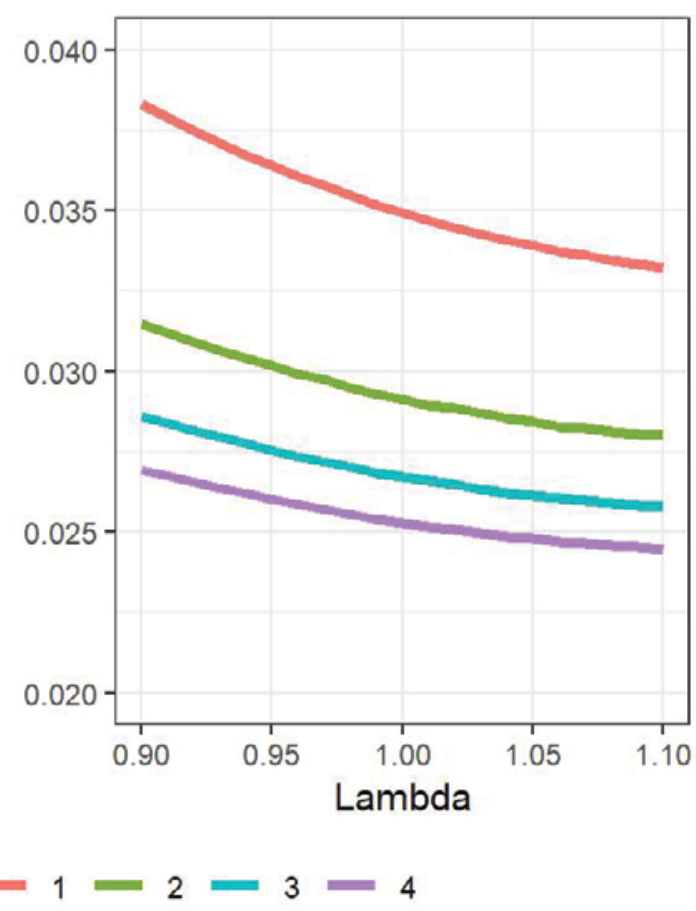

Figure 15. Coefficient of variation when estimating population growth rate at San Nicolas Island, California, for moving 3-year trends during $A, 2018-2021$; and $B, 2019-2022$ when population trend $\lambda$ is reduced to less than 10 percent of the previous 3-year trend (2017-2020). Coefficient of variations are calculated for four different levels of survey effort based on 1, 2, 3, and 4 surveys per year. 
A

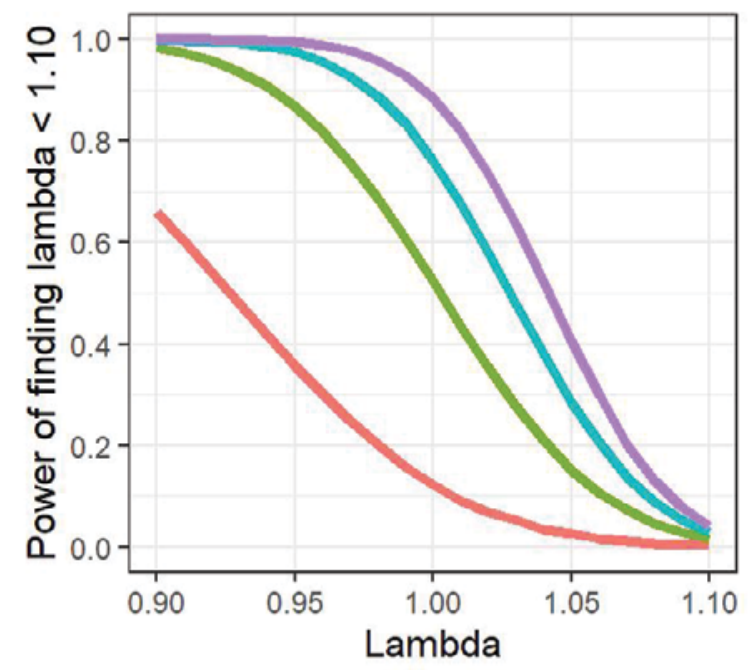

B

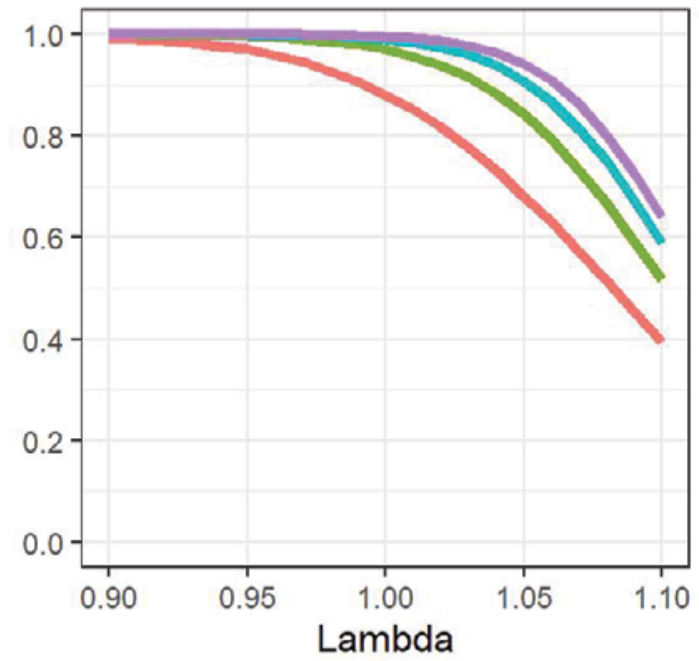

C

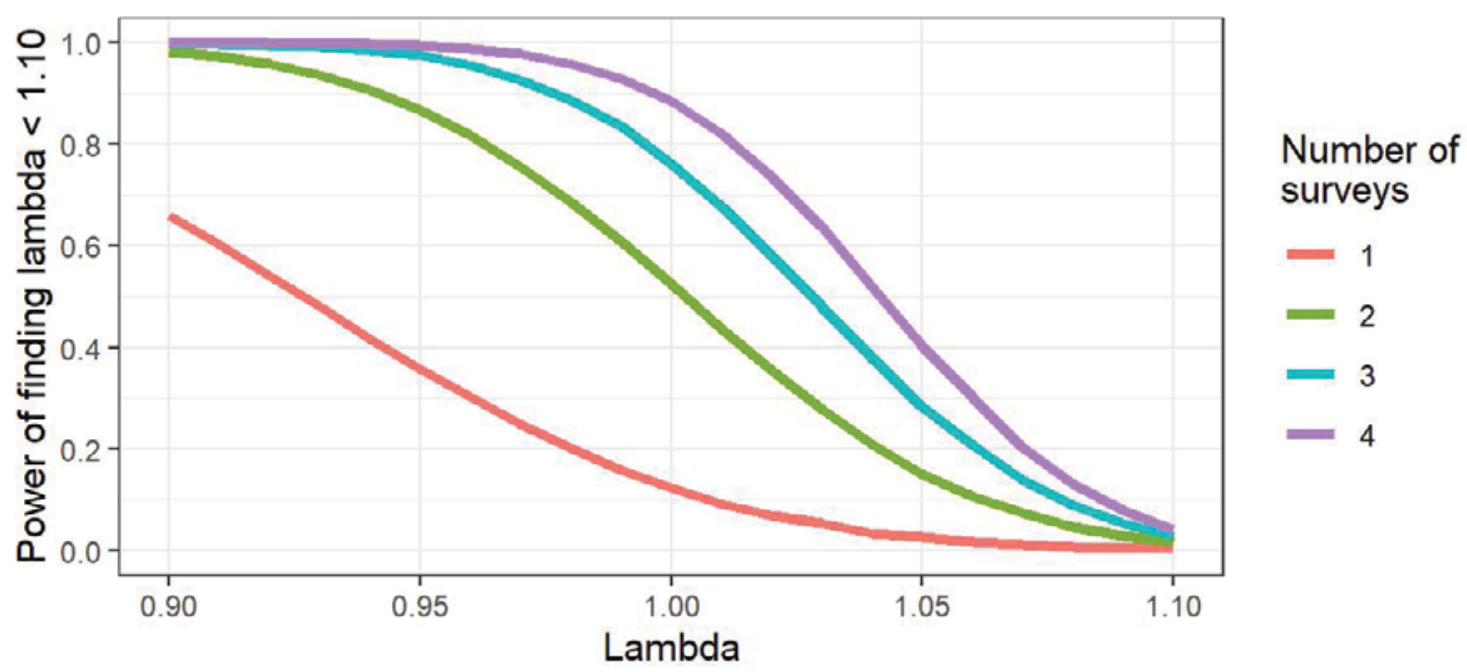

Figure 16. Power of finding that the annual population growth rate, $\lambda$, at San Nicolas Island, California, for a moving 3-year trend in $A$, 2018-2021; $B, 2019-2022$; and $C$, both intervals has been reduced by greater than 10-percent lower than the annual growth rate from the previous 3-year trend $(\lambda=1.22$ during 2017-2020), for example, $\lambda<1$.10. Power is calculated for a range of hypothetical values of $\lambda$ ranging from between 0.90 and 1.10, and four different levels of survey effort based on one, two, three, or four surveys per year. 


\section{Discussion}

Changes are evident in the SNI sea otter population between 2017 and 2020. Most strikingly, population size has grown at an estimated rate of 22 percent per year (95-percent $\mathrm{CI}=11-34$ percent per year) during this interval. This estimate is similar to the growth rates measured in other sea otter populations recovering in the Aleutian Islands, Alaska, British Columbia, and Washington (17.2-25.9 percent per year) and is centered among estimates of the maximum growth rates that can be achieved by sea otter populations (19.6-23.7 percent per year)-theorized based on the reproductive rates, ages of reproductive activity, and average lifespan of females (Estes, 1990). The size of the SNI population was last counted at 114 individuals, which is close to the mean estimate for February 2020 based on LOESS multi-year smoothing regression (fig. 3). Their distribution has shifted and expanded across years and exhibited seasonal variations. Although populations remained most concentrated at the west end of the island, there was increased use of the north side and possibly the south side. The distribution also oscillated seasonally toward greater use of the north and south sides in the winter and spring, then back to the west end during summer and fall. Because sea otters tend to rest on kelp beds and forage underneath in kelp structures, seasonal changes in kelp are likely to be an important driver of the seasonal variations in sea otter distributions that we observed. However, information on kelp distribution is currently limited to images collected annually in the fall. Whether the seasonal increase in use of the north side is related to changes in kelp distribution, the recent population growth, or both, might be determined by additional study, such as increased collection and analysis of seasonal kelp patterns and an examination of historical data to determine if these seasonal changes in sea otter distributions also occurred before the recent population growth.

There are indications that foraging activity could have changed during the past several years and across seasons. Although confidence intervals are rather wide and imprecise, the energy intake rates of sea otters indicate a possible decline during the past several years. Foraging habits are known to change as sea otter populations increase and food resources become more difficult to obtain, and these density-dependent processes can signal that a population is approaching carrying capacity (Estes and others, 2003; Tinker and others 2008; Tinker and others, 2012; Tinker and others, 2019). A decline in forage intake in conjunction with an increase in population size would be expected for a population that is beginning to experience density-dependent effects. However, the rates we measured $(15-21 \mathrm{kcal} / \mathrm{min})$ are comparable to an earlier estimate of $15 \mathrm{kcal} / \mathrm{min}$ based on foraging data collected at SNI during 2003-2005 and similar to other rates typically observed with recently established and rapidly growing populations at sites considered to have abundant resources (12-20 kcal/min; Tinker and others, 2019, fig. 28). By comparison, the intake rates for long-established and stable or slowly growing populations at sites considered to be resource-limited are estimated as less than $10 \mathrm{kcal} / \mathrm{min}$. Furthermore, the 22-percent growth rate of the SNI population is near the maximum rate of growth we would expect for a population that is not experiencing density impacts to foraging resources. However, the shift in urchin prey species going away from large energy-rich red urchins toward smaller purple urchins between 2003 and 2006 and 2017-2020 suggests that changes in composition of preferred prey could be occurring. Additional study would be needed to ascertain patterns in foraging activity, what trends or changes are occurring, and what these patterns tell about sea otter population growth and capacity at SNI.

Foraging results should be interpreted cautiously as the nature of foraging surveys can introduce potential biases that don't occur with population survey counts. Survey effort at SNI was prioritized toward counting sea otters, which occurred on days with the most optimal viewing conditions within each survey interval. Sea otters were systematically counted around the island as synchronously as possible, always within a day, to minimize counting errors due to sea otter movements. These surveys were repeated over multiple days to minimize undercounting due to fluctuating survey conditions, sea otter grouping, behavior and detectability, and we recorded the highest single-day count for each survey as a robust estimate of the population. In contrast, foraging surveys were conducted opportunistically as allowed by time and viewing conditions. As a result, the amount of available foraging information is limited and uneven across surveys, locations, and individual sea otters. Because of limited observations, we aggregated foraging data to compute and compare energy intake rates by year, season, and sex. However, if foraging activity differs by any of these factors, then those effects can potentially confound with these unbalanced aggregations when comparing other factors. Systematic biases also could exist. Foraging observations have an unavoidable bias toward prey acquired during daytime. Previous studies have shown that sea otter foraging bouts occur both during day and night with equal frequency (Tinker and others, 2006). Additionally, data from time-depth recorders implanted in the 2003-2005 SNI study show variation between daytime and nighttime dive characteristics that could result from sea otters seeking different prey nocturnally (Newsome and others, 2010). Furthermore, foraging observations require translation into energy intake values based on prey species and size, and unidentified items are translated into an average value for the size class. The accuracy of these translations depends on detailed and reliable information on the nutritional content of prey items, which have been documented extensively by Oftedal and others (2007), although it remains a work in progress to update and expand these keys for different locations and periods. 
The scope and accuracy of our inferences are directly dependent on the amount of available information. Quarterly surveys enabled us to observe seasonal patterns in distribution and the extent to which those seasonal patterns changed across years. We did not find seasonal patterns in island-wide counts, but we found seasonal variations in distribution around SNI. We used data from the last several years to generate computerized simulations of the power and accuracy to detect greater than 10-percent decreases in population trends if we were to continue quarterly surveys into the next two years compared to fewer surveys that would collect proportionately less information. Multiple surveys (two-four) per year resulted in uniformly greater power than single surveys per year, and the difference in power between two and four surveys depends on the trend threshold being tested as well as the size of the trend underlying the data. We recommend that precision and power be considered when defining the goals and scope of continued monitoring at SNI.

\section{References Cited}

Bion, R., 2020, ggradar - Create radar charts using ggplot2 (R package version 0.2): RDocumentation accessed June 12, 2020, at https://www.rdocumentation.org/packages/ggradar/ versions $/ 0.2$.

Bodkin, J.L., 2015, Historic and contemporary status of sea otters in the North Pacific, chap. 3 of Larson, S.E., Bodkin, J.L., and VanBlaricom, G.R., eds., Sea otter conservation (1st ed.): London, Academic Press, p. 43-61, https://doi.org/10.1016/B978-0-12-801402-8.00003-2.

Estes, J.A., 1990, Growth and equilibrium in sea otter populations: Journal of Animal Ecology, v. 59, no. 2, p. 385-401, https://doi.org/10.2307/4870.

Estes, J.A., and Jameson, R.J., 1988, A double-survey estimate for sighting probability of sea otters in California: The Journal of Wildlife Management, v. 52, no. 1, p. 70-76, https://doi.org/10.2307/3801061.

Estes, J.A., Jameson, R.J., and Johnson, A.M., 1981, Food selection and some foraging tactics of sea otters, in Chapman, J.A., and Pursley, D., eds., Worldwide furbearer conference proceedings: Baltimore, Md., University of Maryland Press, v. 1, p. 606-641.

Estes, J.A., Riedman, M.L., Staedler, M.M., Tinker, M.T., and Lyon, B.E., 2003, Individual variation in prey selection by sea otters-Patterns, causes and implications: Journal of Animal Ecology, v. 72, no. 1, p. 144-155, https://doi.org/10.1046/j.1365-2656.2003.00690.x.
Hatfield, B.B., 2005, The translocation of sea otters to San Nicolas Island-An update, in Garcelon, D.K., and Schwemm, C.A., eds., Proceedings of the Sixth California Islands Symposium: Ventura, California, December 1-3, 2003; Institute for Wildlife Studies, p. 473-475.

Hatfield, B.B., Yee, J.L., Kenner, M.C., and Tomoleoni, J.A., 2019, California sea otter (Enhydra lutris nereis) census results, spring 2019: U.S. Geological Survey Data Series 1118, 12 p., https://doi.org/10.3133/ds1118.

Kenner, M.C., and Tomoleoni, J.A., 2020, Kelp forest monitoring at Naval Base Ventura County, San Nicolas Island, California-Fall 2018 and Spring 2019, fifth annual report: U.S. Geological Survey Open-File Report 2020-1091, 93 p., https://doi.org/10.3133/ofr20201091.

McCullagh, P., and Nelder, J., 1989, Generalized linear model, in Monographs on statistics and applied probability ( $2 \mathrm{~d}$ ed.): London, Chapman \& Hall/CRC, https://doi.org/10.1201/9780203753736.

Newsome, S.D., Bentall, G.B., Tinker, M.T., Oftedal, O.T., Ralls, K., Estes, J.A., and Fogel, M.L., 2010, Variation in $\delta^{13} \mathrm{C}$ and $\delta^{15} \mathrm{~N}$ diet-vibrissae trophic discrimination factors in a wild population of California sea otters: Ecological Applications, v. 20, no. 6, p. 1744-1752, https://doi.org/10.1890/09-1502.1.

Oftedal, O.T., Ralls, K., Tinker, M.T., and Green, A., 2007, Nutritional constraints on the southern sea otter in the Monterey Bay National Marine Sanctuary, and a comparison to sea otter populations at San Nicolas Island, California and Glacier Bay, Alaska: Joint final report to the Monterey Bay National Marine Sanctuary and the Marine Mammal Commission, 23 p.

R Core Team, 2020, The R project for statistical computing: Vienna, Austria, R Foundation for Statistical Computing, https://www.R-project.org/.

Ralls, K., Hatfield, B.B., and Siniff, D.B., 1995, Foraging patterns of California sea otters as indicated by telemetry: Canadian Journal of Zoology, v. 73, p. 523-531, https://doi.org/10.1139/z95-060.

Rathbun, G.B., Hatfield, B.B., and Murphey, T.G., 2000, Status of translocated sea otters at San Nicolas Island, California: The Southwestern Naturalist, v. 45, no. 3, p. 322-328, https://doi.org/10.2307/3672835.

Tinker, M.T., 2015, The use of quantitative models in sea otter conservation, chap. 10 of Larson, S.E., Bodkin, J.L., and VanBlaricom, G.R., eds., Sea otter conservation (1st ed.): London, Academic Press, p. 257-300, https://doi.org/10.1016/B978-0-12-801402-8.00010-X. 
Tinker, M.T., Estes, J.A., Ralls, K., Williams, T.M., Jessup, D., and Costa, D.P., 2006, Population dynamics and biology of the California sea otter (Enhydra lutris nereis) at the southern end of its range: Santa Barbara, California, University of California, Coastal Research Center, Marine Science Institute, Minerals management Service Pacific Outer Continental Shelf Region Study 2006-007, Minerals management Service Cooperative Agreement Number 14-35-0001-31063.

Tinker, M.T., Guimarães, P.R., Jr., Novak, M., Marquitti, F.M.D., Bodkin, J.L., Staedler, M., Bentall, G., and Estes, J.A., 2012, Structure and mechanism of diet specialisation-Testing models of individual variation in resource use with sea otters: Ecology Letters, v. 15, no. 5, p. 475-483, https://doi.org/10.1111/j.1461-0248.2012.01760.x.

Tinker, M.T., Bentall, G., and Estes, J.A., 2008, Food limitation leads to behavioral diversification and dietary specialization in sea otters: Proceedings of the National Academy of Sciences of the United States of America, v. 105, no. 2, p. 560-565, https://doi.org/10.1073/pnas.0709263105.
Tinker, M.T., Tomoleoni, J.A., Weitzman, B.P., Staedler, M., Jessup, D., Murray, M.J., Miller, M., Burgess, T., Bowen, L., Miles, A.K., Thometz, N., Tarjan, L., Golson, E., Batac, F., Dodd, E., Berberich, E., Kunz, J., Bentall, G., Fujii, J., Nicholson, T., Newsome, S., Melli, A., LaRoche, N., MacCormick, H., Johnson, A., Henkel, L., Kreuder-Johnson, C., and Conrad, P., 2019, Southern sea otter (Enhydra lutris nereis) population biology at Big Sur and Monterey, California-Investigating the consequences of resource abundance and anthropogenic stressors for sea otter recovery: U.S. Geological Survey Open-File Report 2019-1022, 225 p., https://doi.org/10.3133/ofr20191022.

U.S. Fish and Wildlife Service, 2012, Final supplemental environmental impact statement on the translocation of southern sea otters: Ventura, Calif., U.S. Fish and Wildlife Service, Ventura Fish and Wildlife Office, 348 p.

Wickham, H., 2016, ggplot2-Elegant graphics for data analysis (2d ed.): New York, Springer-Verlag, 212 p. 


\title{
Appendix 1. Figures of Pages from the Monitoring and Research Plan for Southern Sea Otter Military Readiness Area
}

\author{
U.S. Navy and U.S. Fish and Wildlife Service \\ in coordination with \\ U.S. Geological Survey
}

\section{INTRODUCTION}

The National Defense Authorization Act for Fiscal Year 2016 (NDAA) includes provisions directing the Secretary of the Navy to establish Southern Sea Otter Military Readiness Areas (Areas) at San Nicolas Island and San Clemente Island (Figure 1). Military readiness activities conducted within these Areas are subject to certain exemptions under the Endangered Species Act of 1973, as amended (ESA) and Marine Mammal Protection Act of 1972 (MMPA).

Specifically, with respect to the ESA, Sections 4 and 9 do not apply to the incidental taking of any southern sea otter in the Areas in the course of conducting a military readiness activity, and any sea otter within the Areas is to be treated for the purposes of section 7 as a member of a species that is proposed to be listed as endangered or threatened under the ESA. With respect to the MMPA, Sections 101 and 102 do not apply with respeet to the incidental taking of any sea otter in the Areas in the course of conducting a military readiness activity.

The NDAA also specifies monitoring requirements for these Arcas:

(1) IN GENERAL.- The Secretary of the Navy shall conduct monitoring and research within the Southem Sea Otter Military Readiness Areas to determine the effects of military readiness activities on the growth or decline of the southern sea otter population and on the nearshore ecosystem. Monitoring and research parameters and methods shall be determined in consultation with the U.S. Fish and Wildlife Service (USFW'S).

(2) REPORTS, - Not later than 24 months after the date of the enactment of this section and every three years thereafter, the Secretary of the Navy shall report to Congress and the public on monitoring undertaken pursuant to paragraph (1).

This document contains the research and monitoring plan for the San Nicolas Island Military Readiness Area (SNl Area). Required research and monitoring in this plan are tiered, using population status (increasing, stable, or decreasing) and changes in military readiness activities as triggers for the level of research and monitoring proposed.

Because sea otters do not yet occur at San Clemente Island and may not occur there for decades, preparation of a monitocing plan for the San Clemente Island Military Readiness Area (SCI Area) will not occur until at least three sea otters are present for at least twelve consecutive months or at least one female with a pup is detected. Marine and nearshore natural resource studies and monitoring activities currently ozcur in the areas around $\mathrm{SCl}$ to monitor for other species and habitats of concern. These studies and monitoring events will suffice to detect the presence and persistence of sea otters should they occur in the SCI Area in order to inform at what point a monitoring program under the law will be triggered. This document will be

\footnotetext{
'According to the NDAA, "The term 'military readiness activity' has the meaning given that term in section 315(f) of the Bob Stump National Defense Authorization Act for Fiscal Year 2003 (16 U.S.C. 703 note) and includes all training and operations of the armed forces that relate to combat and the adequate and realistic testing of military equipment, vehicles, weapons, and sensors for proper operation and suitability for combat use,"
}

Figure 1.1. Page 1 of Monitoring and Research Plan for Southern Sea Otter Military Readiness Area. 
reviewed by Navy and USFWS every three years after completion of reports to ensure the plan continues to adequately monitor interactions between military readiness activities and the sea otter population.

Figure 1. Southern Sea Otter Military Readiness Areas.

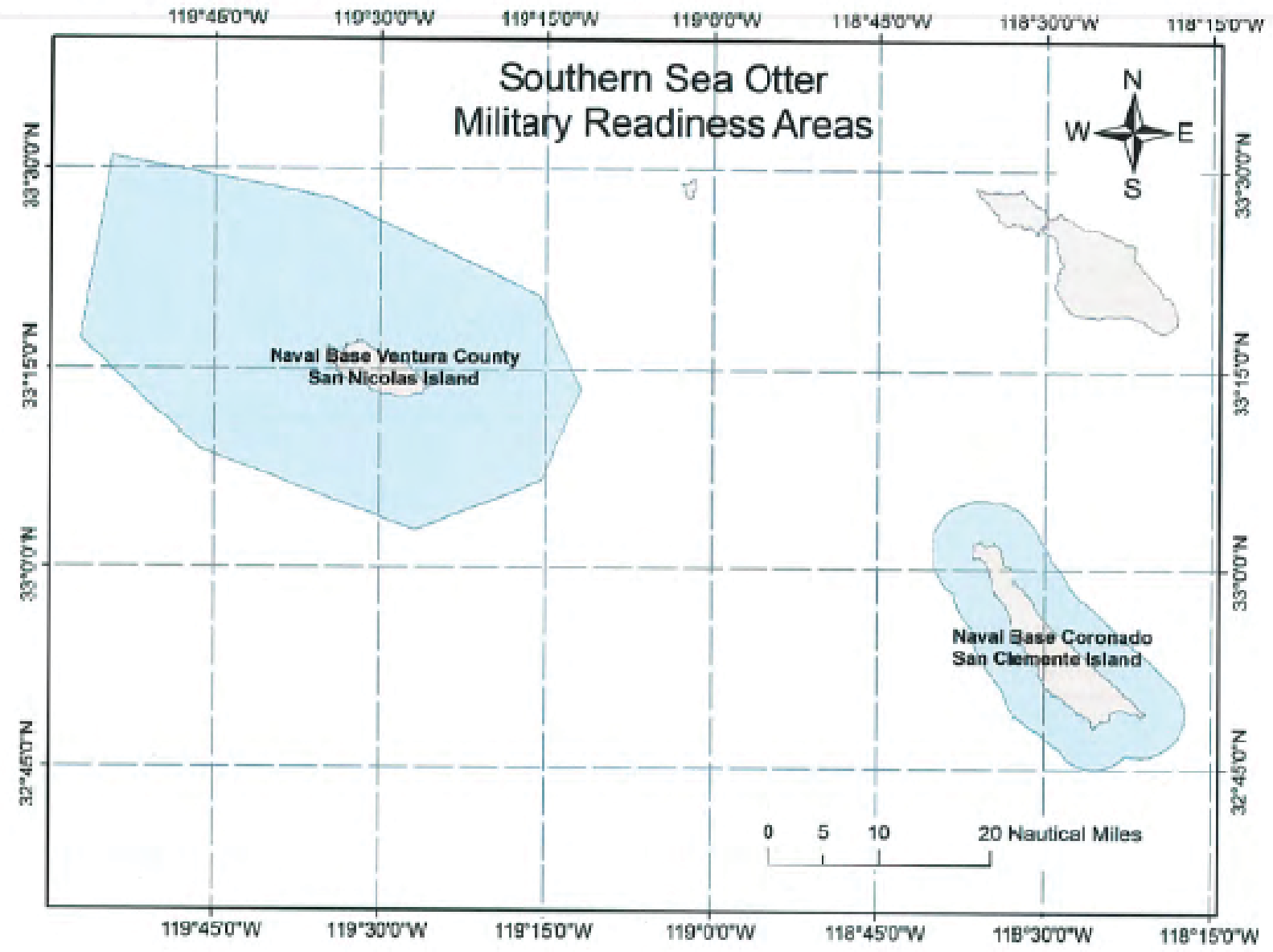

\section{MONITORING AND RESEARCH PLAN FOR THE SNI AREA}

The monitoring plan outlined below and in Figure 2 contains three tiers. The first tier is Basic Monitoring, which represents monitoring and research required given the current status of the sea otter population and currently occurring military readiness activities. Tier 1 efforts will continue as long as military readiness activities remain constant. The second tier is Operational Impact Monitoring. This higher level of monitoring would be required for any new military readiness activity ${ }^{2}$ with a potential to impact sea otters or sea otter habitat. The third tier is Advanced

${ }^{2}$ For the purposes of this plan, a new activity is any activity that would require preparation of an Environmental Assessment or Environmental Impact Statement under NEPA with an area of potential effect within sea otter habitat. Existing activities are described in current NEPA documentation (Appendix 1).

Figure 1.2. Page 2 of Monitoring and Research Plan for Southern Sea Otter Military Readiness Area. 
Monitoring, which is triggered if new military readiness activities, as described in Tier 2, are occurring and any of the following conditicns is also met: (1) a single dead, moribund, or stranded sea otter with injuries consistent with impacts from the activity (as determined by an independent pathologist) is detected; (2) the sea otter population trend at SNI decreases by more than $10 \%$ from the average SNI sea otter population trend over the preceding three-year period ${ }^{3}$ for at least two consecutive years for reasons that cannot be reasonably attributed to anticipated density-dependent reductions in growth (see Tier 1, objective 3); or (3) the total sea otter population at SNI drops below 75. If additional funding or outside partnerships allow, Tier 2 and Tier 3 monitoring may occur even if military readiness activities and sea otter population trends remain stable.

Figure 2. Flow Chart of Required Monitoring.

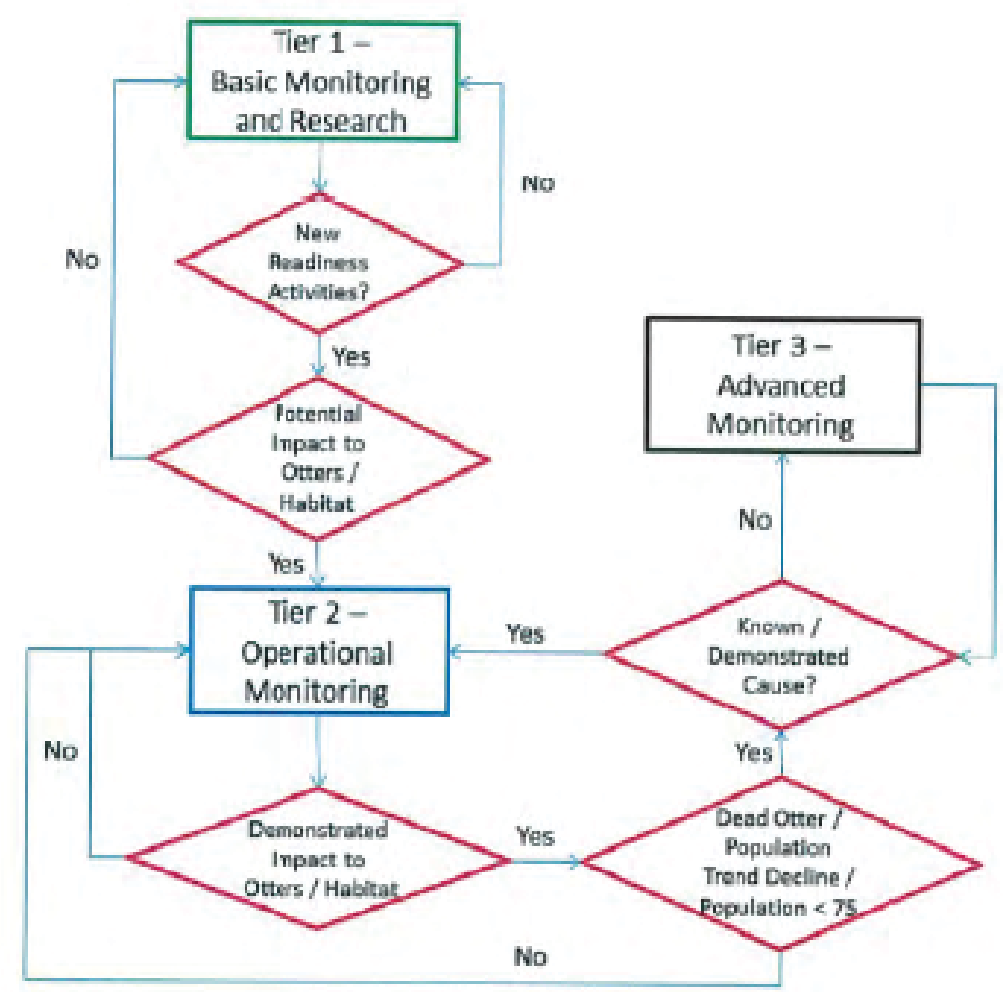

${ }^{3}$ A $10 \%$ decrease in population trend would be determined after correcting for observer or measurement error, using State-Space model analysis of the survey time series or comparable method. Using the current average annual population increase of 1.1 , for example, a $10 \%$ decrease would lead to no increase in population between years (rate of 1.0).

Figure 1.3. Page 3 of Monitoring and Research Plan for Southern Sea Otter Military Readiness Area. 


\section{a. Tier 1 Basic Monitoring and Research}

\section{Objectives for Tier 1 monitoring}

The overarching monitoring goal articulated in the NDAA (to determine the effects of military readiness activities on the growth or decline of the southern sea otter population and on the nearshore ecosystem) can be split into four specific objectives that, taken together, will ensure that this broader goal is achieved. These Objectives are:

1. Monitor and analyze population trends at San Nicolas Island. Data on trends in sea otter abundance are necessary to assess effects of various stressors on the population. In addition to conducting regular surveys, data will be analyzed using dynamical demographic models to infer baseline population parameters (i.e., annual grcwth rates and environmental variability). Such data are necessary but not sufficient on their own to determine causes of population trends.

2. Monitor and analyze subtidal benthic communities and assess impacts of sea otter recovery on food web dynamics. Another core dataset necessary for evaluating impacts on nearshore ecosystem health (with respect to sea otter populations) is monitoring data on benthic subtidal communities, including trends in abundance of foundational species such as kelp and key invertebrates such as urchins and abalone. These data should be analyzed using dynamical multi-species food web models in order to interpret the interacting effects of bottom-up forces (e.g., temperaturc, wave events) and top-down forces (e.g., increasing predation from sea otters).

3. Determine the factors affecting population change. Specifically, assess the relative contributions of density-dependent jactors (changes in per-capita prey abundance) and density-independent factors (e.g. shark mortality, military readiness activities) to variation in growth rates. Extensive research on sea otter populations in California has demonstrated that the most common factor leading to localized reductions in population growth is density-dependent resource limitation. The rate of growth of a local population is generally high at low population densities (as has been the case at San Nicolas over the past 20 years) but will slow as populations approach local carrying capacity. The ultimate factor limiting growth is per-capita prey abundance, although resourcelimitation may be manifested as increased mortality due to disease and emaciation. Therefore, in order to assess whether some other putative threat is influencing population trends at a given location (e.g., shark bite mortality, entanglement in fishing gear, contaminant exposure, etc.), it is necessary first to account for the role of densitydependent factors. Sea otters are almost unique among marine mammals, in that it is possible to accurately infer population status from a number of easily measured indices, including behavioral parameters (foraging success, percent time feeding), individual body condition, and direct measurements of the abundance and size distribution of key prey species, such as sea urchins. By tracking these indices over time, it has been possible in central California to determine the causal role of density-dependent resource limitation in slowing population growth, and this determination should be even more feasible at San Nicolas due to the existence of better baseline data sets. Achieving this objective will be critical for making a meaningful assessment of the effects of other factors on population growth, including military readiness activities.

Figure 1.4. Page 4 of Monitoring and Research Plan for Southern Sea Otter Military Readiness Area. 
Sea Otter Military Readiness Areas Monitoring Plan

August 2016

4. Describe habilat use by sea otters at San Nicolas and identify habitats necessary for vulnerable life history stages and behaviors. Sea otters typically exhibit highly localized patterns of habitat use, which can vary by activity type and by demographic group. For example, resting activity generally occurs in dense kelp canopies, though not all kelp beds are used equally, and certain kelp beds are highly preferred by certain demographic groups (sub-adult males, or females with pups). In contrast, foraging activity more typically occurs along the outer margins of kelp beds and off of emergent rocks. Furthermore, the limited home ranges of most sea otters means that habitat utilization can vary at the scale of kilometers. Understanding home range and habitat use patterns is therefore critical for determining which specific areas around San Nicolas may be most sensitive in terms of the potential for military readiness activities to affect sea otter behavior or health. For example, an area used as resting habitat by reproductive females will be far more sensitive (in terms of the potential to affect population growth) than areas used for feeding by males.

\section{Proposed Study Plan for Tier 1 Monitoring}

To achieve the above four objectives, a multi-faceted approaeh eonsisting of the following tasks is proposed:

Task 1, Objectives 1 and 4. Population Surveys (All Years). An effective survey program for monitoring trends in sea otter abundance at San Nicolas Island is already in place: since the late 1930 s, the USGS has annually conducted between two and four island-wide exhaustive sea otter counts, which are compiled in a GIS-compliant data set on abundance and distributicn (see Tinker and Hatfield 2015). Surveys are currently conducted twice per year (spring and fall) to provide key data on trends in total abundance and also distribution of sea otters around the island. The frequency of these island-wide surveys would be increased to four times per year for the next four years to provide a higher resolution data set on seasonal variation in distribution and habitat use. These surveys would also provide initial data on important habitat areas around SNI. After four years, power analysis of the existing data can be performed to determine whether reduced effort at two surveys per year will be sufficient for accurate estimation of trends and achievement of other objectives (see Tasks 2 through 4).

Task 2, Objectives 2 and 3. Ecosystem Monitoring (All Years). As with Task 1, subtidal monitoring and kelp canopy monitoring programs are already in place, with twice-annual subtidal surveys conducted by USGS for the past 35+ years (Kenner et al., 2013) and annual kelp canopy surveys conducted by the Navy. For USGS subtidal monitoring, data on the ralative abundance of benthic invertebrates, kelps, and fish are collected from seven permanent subtidal sites using standardized SCUBA methods. The resulting data set represents one of the most comprehensive and long-term time series on subtidal ecosystem dynamics worldwide. It can be used to infer the effects of physical disturbance (e.g., large wave events or EI Niño conditions) and food-web perturbations (e.g., the recovery of sea otters, disease outbreaks) on community structure and dynamics. For Navy kelp canopy monitoring, multi-spectral kelp canopy images are collected aumually via aircraft overflight, processed to determine both surface and subsurface kelp canopy to a $30 \mathrm{~cm}$ resolution, and input into a GIS dataset. Subtidal monitoring surveys and kelp canopy overflights would continue at the current frequency.

Figure 1.5. Page 5 of Monitoring and Research Plan for Southern Sea Otter Military Readiness Area. 
Task 3, Objectives 3 and 4. Collection of Foraging Data from Untagged Sea Otters (Years 1-2). A number of key indices for determining the population status of sea otters can be assessed from observational data on sea otter feeding. As food resources become more limiting, sea otter diets become more diverse at the population level and more specialized at the individual level, and the average rate of energy gain decreases (Tinker et al., 2008(b), 2012). Two of these indices (diet diversity and rate of energy gain) can be measured using standardized methods for collecting feeding data from untagged sea otters following previously established protocols (Tinker et al., 2008(b)). Earlier studies of sea otter diet and foraging behavior (1987-93, 2004-07), can be compared with current data to determine how sea otter prey choice and foraging success have changed over the last decade. These data will provide one important step towards achieving Objective 3 and will also allow us to collect baseline data on sea otter distribution, behavior, and habitat use (Objective 4 ). They will also be invaluable for planning future capture and tagging operations, if needed (refer to Tier 3 ). Foraging data collection will occur concurrently with regular surveys for distribution and abundance (Task I).

Task 4. Data Integration, Analysis, and Reporting (All Years). All field data collected will be entered in a geo-referenced Access database. Population dynamics will be analyzed using published methods to model sea otter populations (Clark and Bjørnslad, 2004; Tinker, 2015; Tinker et al., 2006). Data on sea otter locations and habitat use will be analyzed in GIS using spatial tools and compared with ecosystem and habitat data. Statistical analysis may include logistical regression (habitat use vs availability), Maximum Entropy Models and General Additive Model (GAM). A series of high resolution GIS digital maps will be created to summarize all spatial data and analysis results and to facilitate identification of important habitats for sea otters (habitats most frequently used for feeding and resting).

To evaluate ecosystem-effects of sea otter populations at San Nicolas Island (Objective 2), an existing Ecopath mass-jalance food web model for sea otters and kelp forests will be modified by combining the dietary data collected during this project and the concurrent subtidal monitoring data (see Kenner et al., 2013), and projections of food web dynamics in response to sea otter predation will be conducted using Ecopath/Ecosim. Community interaction matrix approaches will be used to analyze and forecast food web dynamics. Both approaches will allow us to estimate the range and magnitude of ecosystem services associated with the recovery of sea otters.

\section{b. Tier 2 Operational Monitoring}

\section{Objective for Tier 2 Monitoring}

Operational monitoring under Tier 2 would be required for any new military readiness activity with a potential to impact sea otters or sea oter habitat. At present there are no proposed new military readiness activities with potential to impact sea otters or sea otter habitat and there are no data suggesting continuing activities demonstrate significant disturbance effects. Furthermore, the existence of a measurable disturbance effect would not by itself imply an impact on population growth (indeed, the relatively rapid rate of population growth at San Nicolas Island compared to the mainland population over the past 20 years would suggest that there have been minimal or no effects of disturbance on sea otter populations to date). Rather, the benefit of examining this question would be to provide useful data on the types of disturbance that elicit a response and the contexts in which effects on behavior or energy expenditure are most likely to

Figure 1.6. Page 6 of Monitoring and Research Plan for Southern Sea Otter Military Readiness Area. 
occur. Such information could be useful for planning purposes in future military readiness activities and for identifying potential problems before they occur.

I. Assess the effects of disturbance on behavior and energetics. In order to determine whether new military readiness activities have the potential to affect sea otter populations, it will be helpful to elucidate the likely mechanisms by which such an effect would occur. Specifically, eertain types of activities may elicit a behavioral response (disturbance) and possibly impact individual energy expenditure (depending on the magnitude of response to the disturbance).

\section{Proposed Study Plan for Tier 2 Monitoring}

To achieve this objective, the following task is proposed for new military readiness activities at SNI with a potential to impact sea otters or sea otter habitat:

Task 1. Real-time Monitoring of Sea Otter Reactions. For any new military readiness activity with a potential to impact sea otter behavior, real-time monitoring of sea otter responses to the activity will occur. To detect behavioral responses and distinguish these from background levels of activity, a "Before-After-Control-Impact" (BACI) design will be used. The BACI experimental design requires sampling to be conducted at both control sites and "impact" (treatment) sites at repeated intervals before and during/after the activities in question. Behavioral sampling will be conducted using one of three methods: (1) If possible, sea otters will be monitored by Navy biologists using high-power telescopes from shore, after receiving training from USGS biologists in standardized scan-sampling methods for measuring the behavior of sea otters. Training will cover basic scan sampling protocols and the categorization of behaviors using standard sea otter ethograms. Note that direct monitoring can occur only if sea otters are present in areas visible by telescope and outside hazard patterns that preclude human presence; (2) Unmanned aerial vehicles (UAVs) may be used to observe sea otters either farther from shore or during events when hazard patterns preclude human presence. UAVs will be equipped with high-resolution video cameras that allow the observation of behavioral changes. In the case of this option, Navy personnel will work with USGS biologists to validate UAV data collection techniques via comparisons with data collected by human observers; (3) If in place, archival data logging tags described under Tier 3 monitoring would replace the previous two methods (see below).

\section{c. Tier 3 Advanced Monitoring}

\section{Objective for Tier 3 Monitoring}

Advanced monitoring would be required in the event that new military readiness activities as described in Tier 2 are occurring and any of the following conditions is also met: (1) a single dead, moribund, or stranded otter with injuries consistent with impacts from the activity (as determined by an independent pathologist) is detected; (2) the see otter population trend at SNI decreases by more than $10 \%$ from the average trend over the preceding three-year period for at least two consecutive years for reasons that cannot be reasonably attributed to anticipated density-dependent reductions in growth (see Tier 1, objective 3); or (3) the total sea otter population at SNI drops below 75. This monitoring would focus on providing a more detailed analysis of habitat use, emigration (if occurring), and reactions to specific activities. If no substantial effect from military readiness activities on sea otter health is detected and a reason for

Figure 1.7. Page 7 of Monitoring and Research Plan for Southern Sea Otter Military Readiness Area. 
the declining growth trend is known (e.g., shark bite mortality or food limitation, as substantiated by other monitoring), Tier 3 monitoring would not be required.

After a second consecutive year of change by more than $10 \%$ from the current sea otter population trend following the occurrence of new military readiness activities, the Navy will seeure funds as quickly as possible to initiate any advanced monitoring requirements. Advanced monitoring will begin when these new funds become available. Advanced monitoring may also benefit earlier objectives, as described, and will be supported prior to the Tier 3 trigger if additional funding or partnerships become available.

\section{Proposed Study Plan for Tier 3 Monitoring}

To achieve this objective, the following tasks are proposed:

Task 1. Capture, Tagging, and Sampling. In compliance with all applicable Federal laws and statues, a sample of approximately 25 sea otters at San Nicolas Island will be captured and tagged, following methods utilized for many similar studies in the past, including one conducted previously at San Nicolas Island (Tinker et al., 2008(a)). Captures are conducted by a highly experienced and uniquely trained sea otter capture team using specialized closed-circuit SCUBA methods (Ames et al., 1983). Divers swim out from small skiffs, guided by radio transmissions form the skiff operator and shore-spotters, and position underneath a potential resting sea otter. The divers then swim upwards and entrap the resting animal in a Wilson trap attached to an underwater propulsion device. The captured animals are then transported back to a support vessel for processing by a veterinary team.

All captured animals will be anaesthetized and tagged and will receive comprehensive health exams and bio-sampling. Each animal is equipped with colored flipper tags for visual identification, a surgically implanted VHF transmitter for radio tracking, and a time-depth recorder (TDR) for bio-logging of diving activity. VHF frequencies will be deconflicted with Navy working frequencies to avoid any mission impact. Analysis of morphometric data and health parameters, and comparison of these with other sub-populations in California and with previously captured animals at San Nicolas Island (2005-07), will also contribute towards accomplishing Tier 1, Objective 3.

Task 2, Telemetry-based Monitoring of Tagged Animals (2Years). After release, study animals will be monitored regularly (using standardized VHF telemetry protocols) by shore-based observers. This phase will continue for two years past tagging (pending support for follow-on work). Field personnel will conduct shore-based daily surveys of the study site using standard telemetric protocols (triangulation on radio signal using VHF telemetry receivers and visual identification using 50-80X Questar spotting scopes: see Tinker et al., 2006, 2008) to locate all study animals within the study area and record precise GPS position, survival, reproductive status, and instantaneous behavior. Attempts will be made to re-sight all study animals at least five times per week. A series of intensive focal-animal observation sessions will be established to collect detailed hehavioral data. Diring these 12-hour focal animal monitoring sessions, data will be recorded at 10-minute intervals on the individual's activity state, diet, dive behavior, distance-to-shore and fine-scale movements (habitat use). Whenever study animals feed during these activity sessions, continuous data will be recorded on dive/surface intervals and prey capture rates and handling times following previously established protocols (Tinker et al., 2008 (b)). The anticipated schedule of focal-animal observation sessions is two sessions per

Figure 1.8. Page 8 of Monitoring and Research Plan for Southern Sea Otter Military Readiness Area. 
week, with a goal of obtaining three sessions for each study animal. These data, and comparisons with similar data from other populations, provide additional information for characterizing habitat use patterns (Tier 1, Objective 4), foraging success and status with respect to prey resources (Tier 1, Objective 3), and predator-prey interactions and ecosystem impacts (Tier 1, Objective 2).

Task 3. TDR Retrieval and Analysis. After two years of deployment, a second capture operation will recapture previously tagged otters. Recaptured animals will undergo another surgery in order to retrieve the implanted TDR (containing two years of bio-logged diving and temperature data), and a second set of morphometric and bio-health samples will be collected. Note that at this time a subcutaneous networking tag programmed for short-distance communications and data sharing between otters (and between otters and a buoy equipped with a data retrieval unit) would be implanted. Data from the retrieved TDR units will be downloaded and analyzed, following established methods, in order to obtain detailed information on time-activity budgets, foraging behavior and diving depth, and reproductive parameters, thereby contributing to Tier 1 , Objectives 3 and 4 . Because the data on behavior have a high resolution (2-second interval between depth readings), it will be possible to relate changes in activity to specific events that occurred over the two-year period, thereby contributing to the Tler 2 objective of identifying reactions to specific events. Existing Navy data on operational dates and times will be used to cross-reference with TDR data.

Figure 1.9. Page 9 of Monitoring and Research Plan for Southern Sea Otter Military Readiness Area. 
Sea Otter Military Readiness Areas Monitoring Plan

August 2016

\section{LITERATURE CITED}

Ames, J. A., R. A. Hardy, and F. E. Wendell. 1983. Tagging materials and methods for sea otters, Enhydra lutris. California Fish and Game 69:243-252.

Clark, J. S. and O. N. Bjernstad. 2004. Population time series: Process variability, observation errors, missing values, lags, and hidden states. Ecology 85:3140-3150.

Kenner, M. C., J. A. Estes, M. T. Tinker, J. L. Bodkin, R. K. Cowen, C. Harrold, B. Hatfield, M. Novak, A. Rassweiler, and D. C. Reed. 2013. A multi-decade time series of kelp forest community structure at San Nicolas Island, California (USA). Ecology 94:2654. doi:10.1890/13-0561R.1

Tinker, M. T. 2015. The Use of Quantitative Models in Sea Otter Conservation. Pages 257-300 in J. L. Bodkin, G. R. Vanblaricom and S. Larson eds. Sea Otter Conservation. Elsevier, London, UK.

Tinker, M.T. and B. B. Hatfield. 2015. Southwest U.S. Southern sea otter annual range-wide census results: U.S. Geological Survey data release, http://dx.doi.org/10.5066/F7F47M5C

Tinker, M. T., D. F. Doak, and J. A. Estes. 2008(a). Using demography and movement behavior to predict range expansion of the southern sea otter. Ecological Applications 18:1781-1794.

Tinker, M. T., D. F. Doak, J. A. Estes, B. B. Hatfield, M. M. Staedler and J. L. Bodkin. 2006. Incorporating diverse data and realistic complexity into demographic estimation procedures for sea otters. Ecological Applications 16:2293-2312.

Tinker, M.T., J.A. Estes and G. Bentall. 2008(b). Food limitation leads to behavioral diversification and dietary specialization in sea otters. Proceedings of the Nationel Academy of Sciences 105:560-565.

Tinker M.T., P. R. Guimarães, M. Novak, F. M. D. Marquitti, J. L. Bodkin, M. Staedler, G. Bentall, and J. A. Estes. 2012. Structure and mechanism of diet specialization: testing models of individual variation in resource use with sea otters. Ecology Letters 15:475-483.

Figure 1.10. References for Monitoring and Research Plan for Southern Sea Otter Military Readiness Area. 


\author{
Appendix 1 \\ List of Current Navy NEPA documents \\ San Nicolas Island
}

\begin{tabular}{|c|c|c|}
\hline Document Title & Date & Brief Description \\
\hline $\begin{array}{l}\text { Environmental Assessment Directed Energy } \\
\text { Test Facilities at San Nicolas Island }\end{array}$ & 2015 Jun & $\begin{array}{l}\text { Directed Energy test facility } \\
\text { construction and operations }\end{array}$ \\
\hline $\begin{array}{l}\text { Environmental Assessment/Overseas } \\
\text { Environmental Assessment Point Mugu Sea } \\
\text { Range Expansion of Unmanned Systems } \\
\text { Operations }\end{array}$ & 2015 Feb & $\begin{array}{l}\text { Increased use of both unmanned } \\
\text { aerial vehicles and unmanned } \\
\text { surface vehicles on the Sea Range }\end{array}$ \\
\hline $\begin{array}{l}\text { Enwironmental Assessment Point Mugu Sea } \\
\text { Range Countermeasures }\end{array}$ & $2014 \mathrm{Jul}$ & $\begin{array}{l}\text { Use of various countermeasures, } \\
\text { including guns, directed energy, } \\
\text { chaff, flares, and others on the } \\
\text { Sea Range }\end{array}$ \\
\hline $\begin{array}{l}\text { Final Environmental Assessment for } \\
\text { Obtaining California Sea Lions for Service in } \\
\text { the Navy Marine Mammal Program }\end{array}$ & 2012 Dec & $\begin{array}{l}\text { Collection of live sea lions from } \\
\text { San Nicolas Island }\end{array}$ \\
\hline $\begin{array}{l}\text { Final Environmental Assessment/Overseas } \\
\text { Environmental Assessment Laser Testing and } \\
\text { Training Naval Air Warfare Center Weapons } \\
\text { Division Sea Range, Point Mugu, California }\end{array}$ & 2010 Jun & $\begin{array}{l}\text { Testing and training with lasers at } \\
\text { Point Mugu and San Nicolas } \\
\text { Island }\end{array}$ \\
\hline $\begin{array}{l}\text { Final Environmental Assessment SSM-1 KAI } \\
\text { Missile Testing at San Nicolas Island }\end{array}$ & 2007 Mar & $\begin{array}{l}\text { Testing and training with } \\
\text { Japanese Defense Forces missile } \\
\text { system }\end{array}$ \\
\hline $\begin{array}{l}\text { Environmental Assessment FOCUS Cable } \\
\text { Repair - San Nicolas Island, CA }\end{array}$ & 2003 Sep & $\begin{array}{l}\text { Repair of undersea fiber optic } \\
\text { cable }\end{array}$ \\
\hline $\begin{array}{l}\text { Arrow System Improvenent Program } \\
\text { Enwironmental Assessment }\end{array}$ & $2003 \mathrm{Nov}$ & $\begin{array}{l}\text { Testing and training with Israeli } \\
\text { Defcnsc Forces missile system }\end{array}$ \\
\hline $\begin{array}{l}\text { Final Environmental Impact } \\
\text { Statement/Overseas Environmental Impact } \\
\text { Statement Point Mugu Sea Range }\end{array}$ & 2002 March & $\begin{array}{l}\text { Programmatic coverage for Sea } \\
\text { Range testing and training } \\
\text { activities }\end{array}$ \\
\hline $\begin{array}{l}\text { Construction and Operation of a Supply Pier } \\
\text { on San Nicolas Island }\end{array}$ & 2002 Sep & $\begin{array}{l}\text { Pier constructions at San Nicolas } \\
\text { Island }\end{array}$ \\
\hline $\begin{array}{l}\text { Final Environmental Assessment/Overseas } \\
\text { Environmental Assessment Harpoon BLOCK } \\
\text { II Development Test } 2 \text { on the Point Mugu } \\
\text { Sea Range }\end{array}$ & $2001 \mathrm{Dec}$ & $\begin{array}{l}\text { Testing and training with } \\
\text { Harpoon missile systems on Sea } \\
\text { Range }\end{array}$ \\
\hline $\begin{array}{l}\text { Addendum to the EA for Tomahawk Flight } \\
\text { Test Operations on the West Coast of the } \\
\text { United States }\end{array}$ & 2000 Nov & $\begin{array}{l}\text { Addition of a soft-landing area on } \\
\text { San Nicolas Island for Tomahawk } \\
\text { missile system testing and } \\
\text { training. }\end{array}$ \\
\hline $\begin{array}{l}\text { Final Environmental Assessment - } \\
\text { Tomahawk Flight Test Operations on the }\end{array}$ & 1998 Oct & $\begin{array}{l}\text { Testing and training with } \\
\text { Tomahawk missile systems on }\end{array}$ \\
\hline
\end{tabular}

A-1

Figure 1.11. Page A-1 of appendix 1 for Monitoring and Research Plan for Southern Sea Otter Military Readiness Area. 
Sea Otter Military Readiness Areas Monitoring Plan

August 2016

\begin{tabular}{|c|c|c|}
\hline Document Title & Date & Brief Description \\
\hline West Coast of the United States & & the Sea Range \\
\hline $\begin{array}{l}\text { Environmental Assessment Non-warhead } \\
\text { Standoff Land Attack Missile (SLAM) } \\
\text { Expanded Response (ER) Developmental } \\
\text { Test \& Evaluation Firings San Nicolas Island, } \\
\text { Ventura County, California }\end{array}$ & 1997 Oct & $\begin{array}{l}\text { Construction and operation of an } \\
\text { inert (non-warhead) target site } \\
\text { on San Nicolas Island }\end{array}$ \\
\hline $\begin{array}{l}\text { Environmental Assessment of the Use of the } \\
\text { Outer Sea Test Range for the Shock Trial of } \\
\text { The DDG } 53\end{array}$ & $1994 \mathrm{Apr}$ & $\begin{array}{l}\text { Shock trial for a specific Navy } \\
\text { Destroyer }\end{array}$ \\
\hline $\begin{array}{l}\text { Environmental Assessment, Fiber Optic } \\
\text { Communication Undersea System (Focus) }\end{array}$ & 1989 Mar & $\begin{array}{l}\text { Installation of an undersea fiber } \\
\text { optic cable between Point Mugu } \\
\text { and San Nicolas Island }\end{array}$ \\
\hline
\end{tabular}

A-2

Figure 1.12. Page A-2 of appendix 1 for Monitoring and Research Plan for Southern Sea Otter Military Readiness Area. 
For more information concerning the research in this report, contact the Director, Western Ecological Research Center

U.S. Geological Survey

3020 State University Drive East

Sacramento, California 95819

https://www.usgs.gov/centers/werc

Publishing support provided by the U.S. Geological Survey Science Publishing Network, Sacramento Publishing Service Center 
